Supplement of Saf. Nucl. Waste Disposal, 1, 289-290, 2021

https://doi.org/10.5194/sand-1-289-2021-supplement

(c) Author(s) 2021. CC BY 4.0 License.

Supplement of

\title{
Long-term storage of information about nuclear waste. 100000 years and beyond
}

\author{
Martin Kunze \\ Correspondence to: Martin Kunze (m.kunze@ memory-of-mankind.com)
}

The copyright of individual parts of the supplement might differ from the article licence. 


\section{Information Carriers with Unlimited Longevity \\ Even Under Extreme Conditions}

This keynote is about how knowledge can lead to informed decisions

But the "how" is not only about the intellectual process, it is also about the physical limits of keeping information at all.

In order to make decisions, knowledge needs to be transmitted into the future : 100 years, 1000 years or 100.000 years

I will present a short analysis of conventional data carriers,

compare their durability and capacity and

introduce durable information carriers

and finally present a suggestion for a Nuclear Message for marking a deep geological repository. 


\title{
NEA/IDKM/EGAP \\ Expert Group for Awareness Preservation
}

\author{
Information, Data and Knowledge \\ Management (IDKM) of radioactive \\ waste management
}

I am Martin Kunze, Chair NEA, Expert Group for Awareness Preservation .

Awareness in this case means awareness of the existance of a nuclear site

My background is ceramic and silicate technologies, I am founder of the Memory of Manind project, Expert for long term data storage, archives

Nuclear waste consists of dangerous though precious materials. The concept of sustainability and responsible usage of resources prompted the demand not to bury and isolate nuclear waste from the biosphere and forget it forever, but rather to leave the information about it in such a way that future generations can make their own informed decisions how to further proceed with the site.

And even if the transmission of information is interrupted, it should then be possible for a technically industrialized society to reconstruct this information.

The materials that we store in deep underground, especially in places where one would not geologically expect it, could represent valuable resources for future generations. 


\section{NEA/IDKM/FGAP Expert Group for Awareness)Preservation}




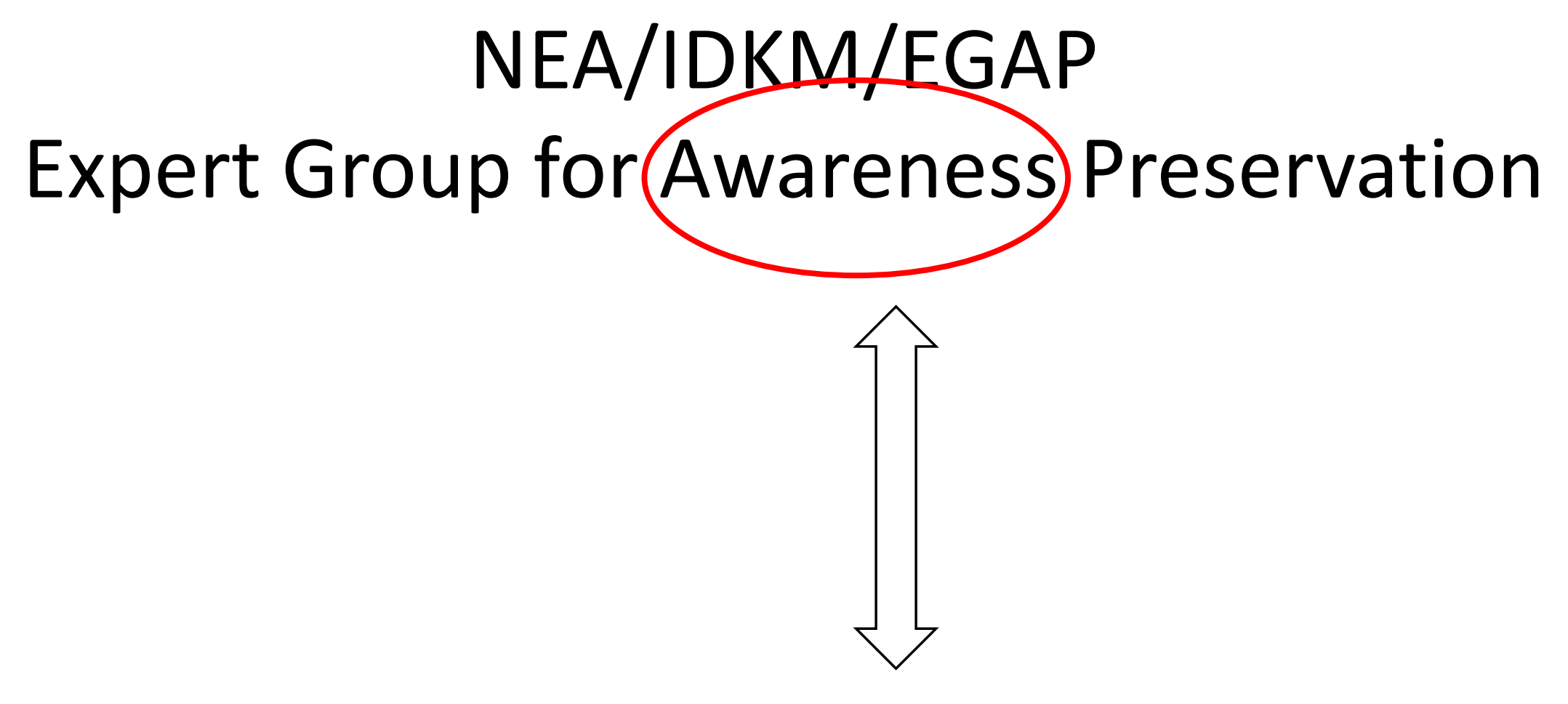

Information 


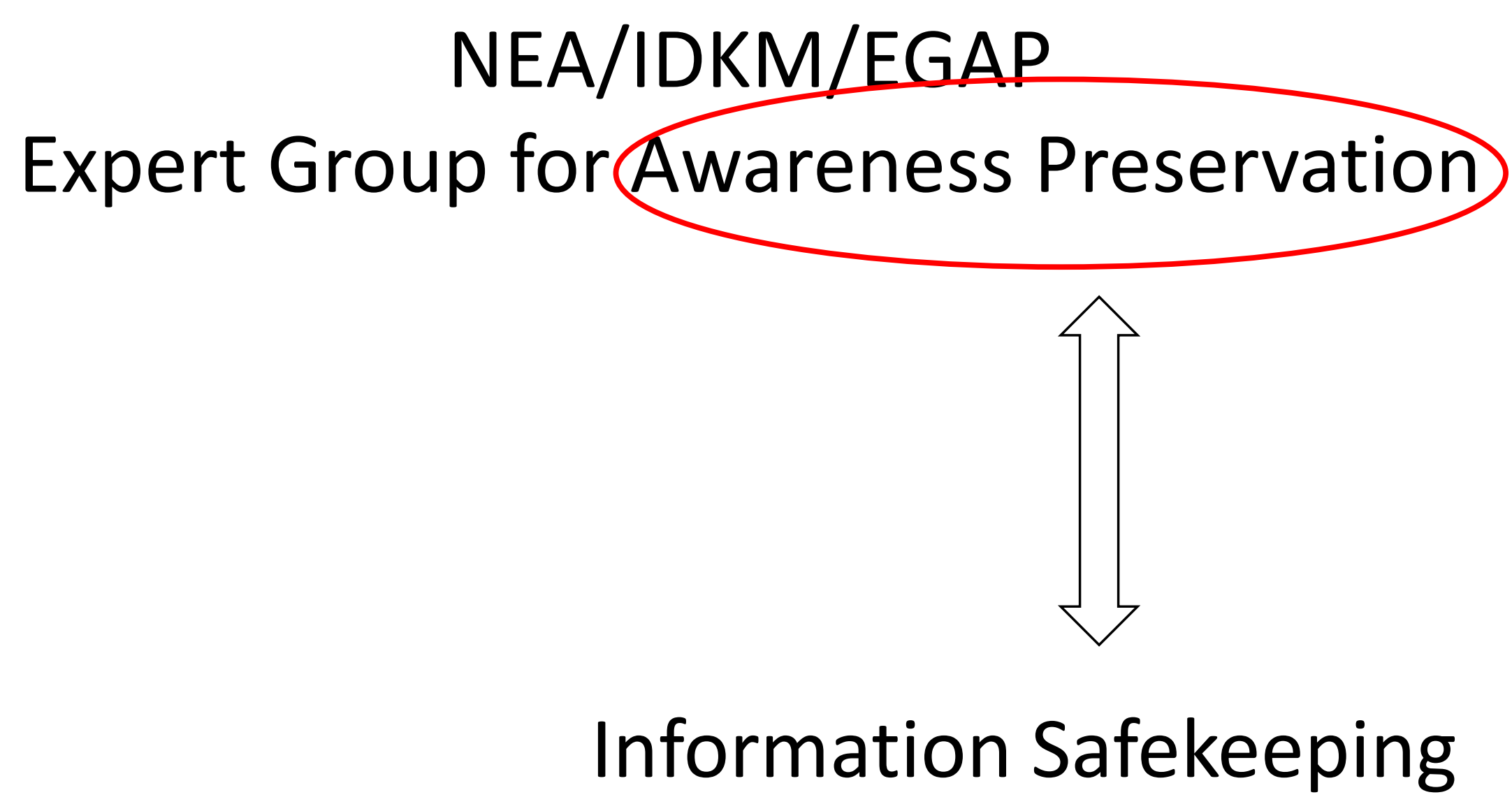




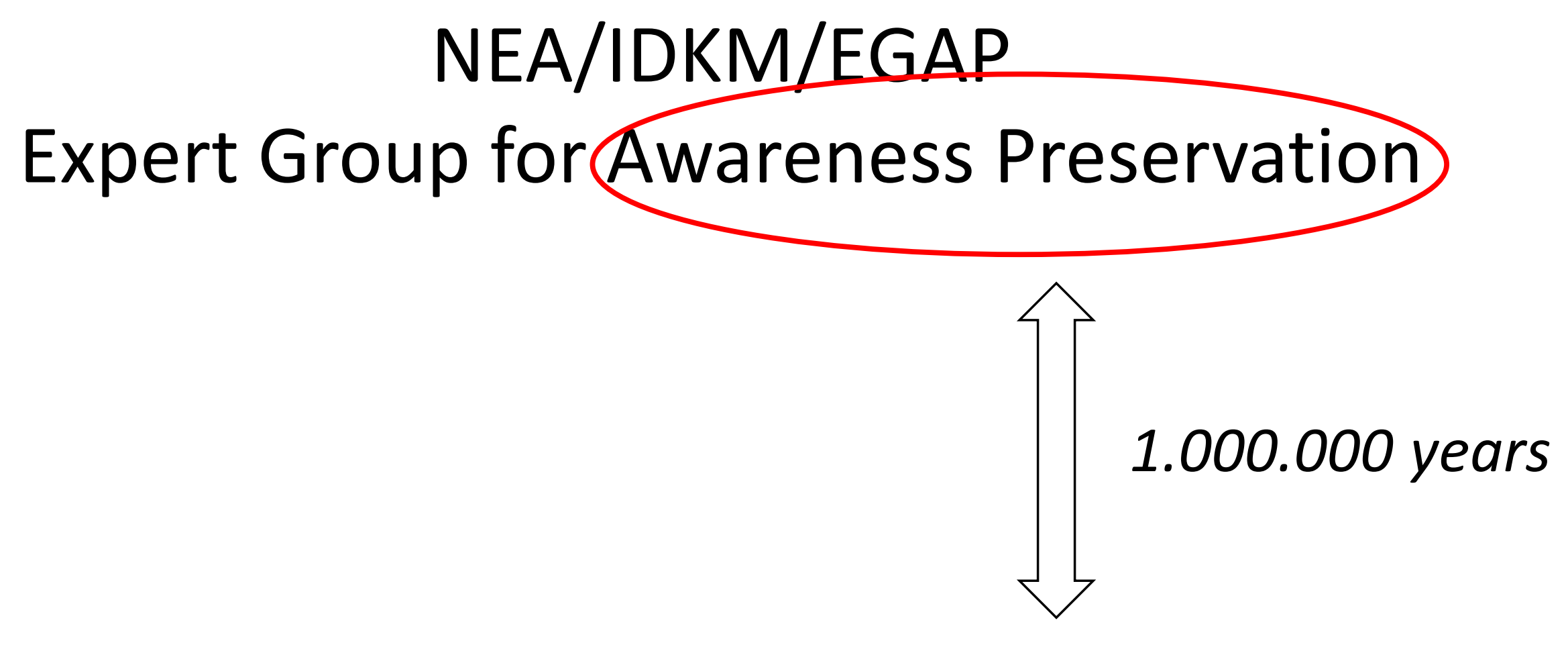

Long Term Information Safekeeping

The solutions to keep information in order to create awareness should cover a time period of information storage, unprecedented in human history. 


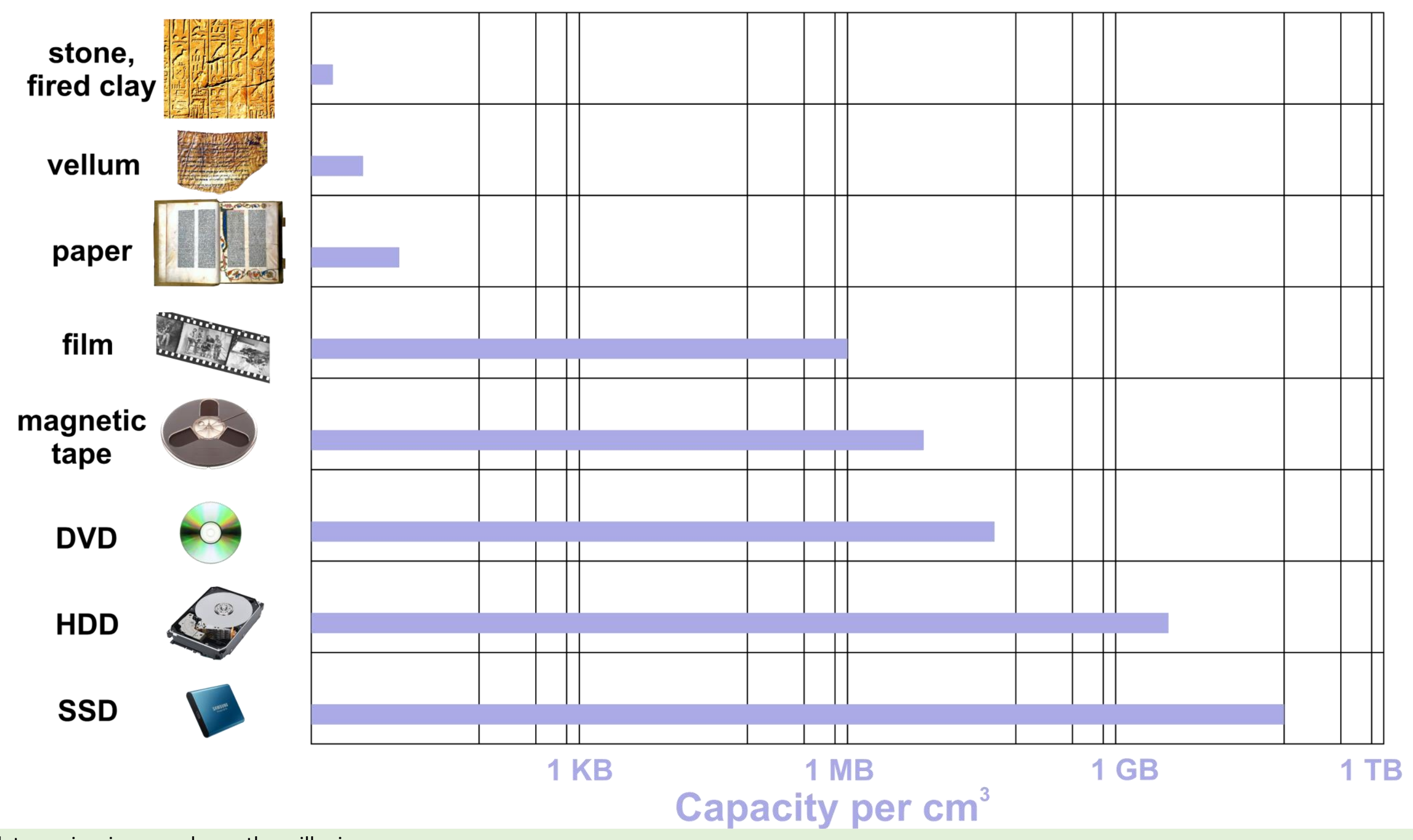




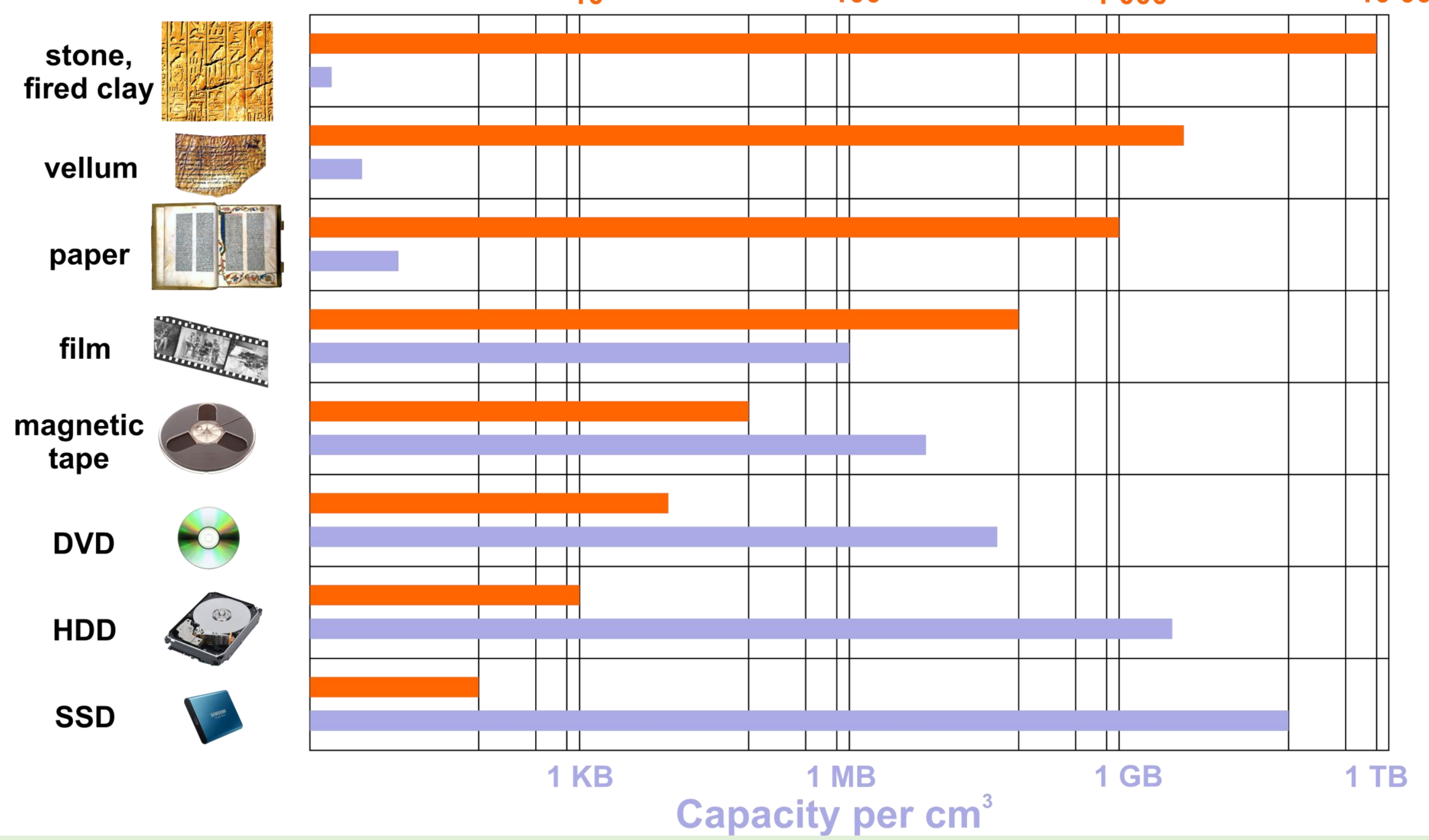

whereas in the same way the durability increased, it seems to be inversly proportional. 


\section{Limits of Long Term Information Storage}
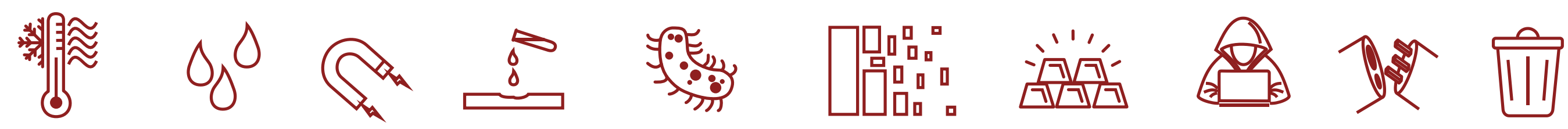

Today's most widely used data carriers permanently consume energy - not eligible on the long run.

Temperature and humidity needs to be controlled, microfilm for example has a durability of 500 years at $5^{\circ} \mathrm{C}$ and $50 \%$ humidity. The durability significantly decreases when parameters change.

A magentic pulse e.g. from a solar storm, destroys data carriers.

Erosive gases destroy optical data carriers.

Microbes infest paper but also film and organic materials of optical data carriers.

Self degradation is not only a problem of color photos or microfilm, but also of SD memory cards. The reason why a flash memory can hold huge amounts of data in incredibe tiny space is also the reason for ist decay: quantum effects.

Precious materials, such as platinum or gold as non corroding data carrier is not the best idea. egyptian tombs were robbed, not because of the nice statues, but for the material they were made of.

cyber attacks can block data from access

incompatibility of systems, languages or formats, hard- and software create problems that lead to inaccessibility of data

Inadverted deletion, loss of access keys, or loss of data structure, lead to situations where data somewhere exists but cannot be retrieved.

And finally profusion: The larger the overall amount of existing data, the harder it gets to mark a dataset as significant. 


\section{Ceramic as Basis for Data Carriers}

My background is ceramic and silicate technologies.

About 10 years ago I started to use a new printing technology, which was originally developed to print company logos on coffee cups with fine color glazes.

I misused this technology to print images and text onto bathroom tiles, which resulted in the most durable data carriers ever. 


\section{Proof of Concept}

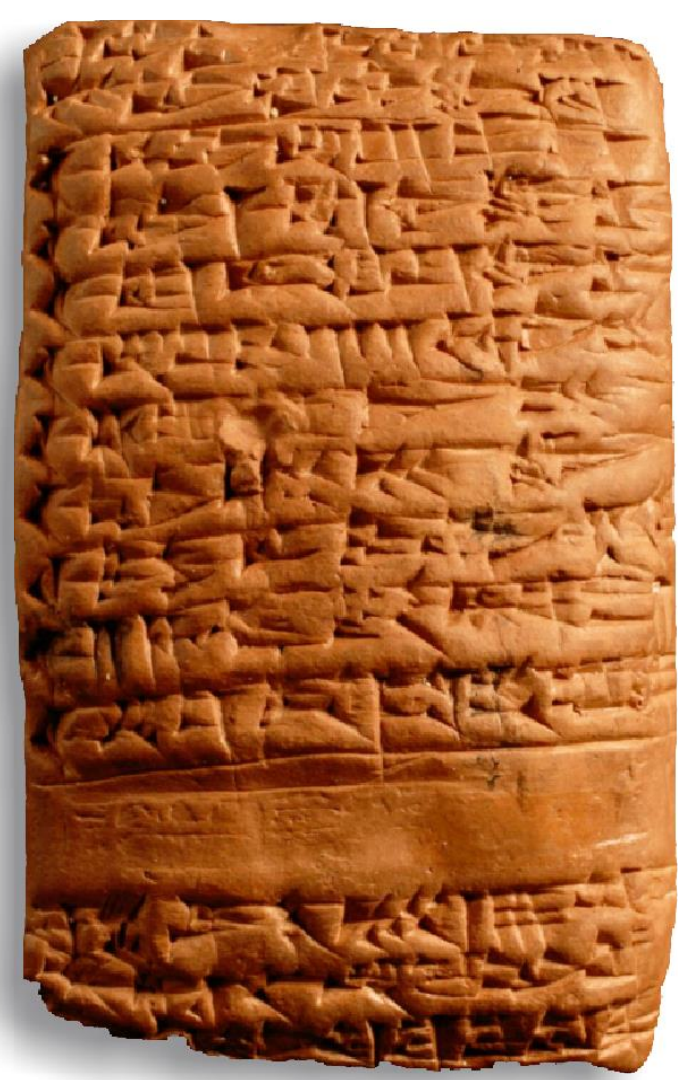

\section{0 years}

That ceramic works as data carrier is impressively proven by babylonian cuneiform tablets. 


\section{High Quality Tiles with Ceramic Color Print}
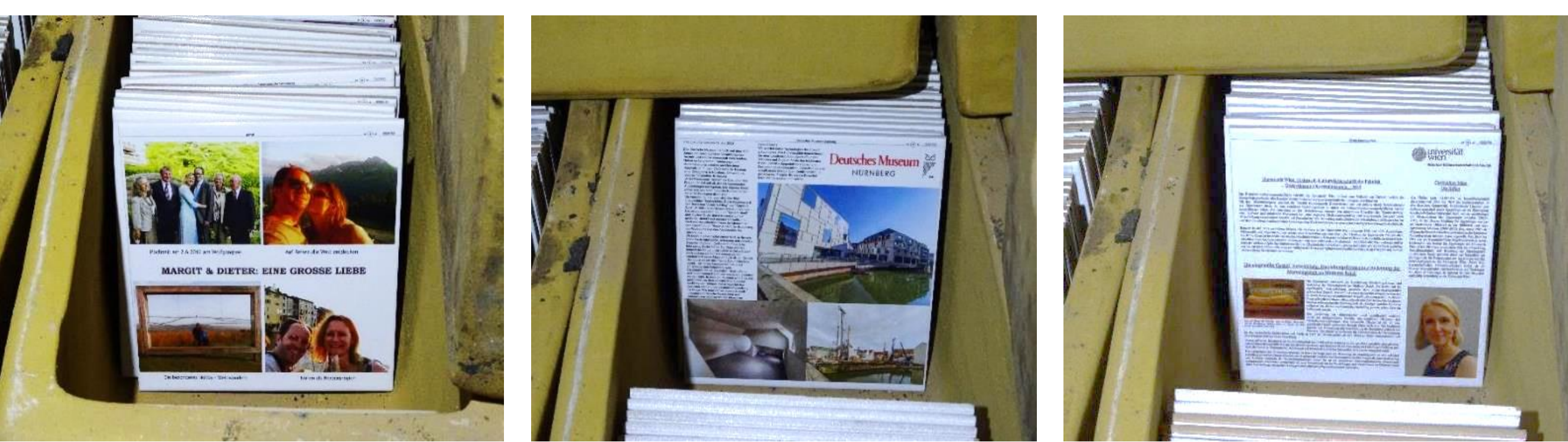

Institutions such as universities or museums store PhD-theses, most important objects of the collection or present MOM tablets as awards for outstanding scientific research.

Additionally, individuals also contribute to MOM by describing their families or weddings or sending an entire story of life into the future.

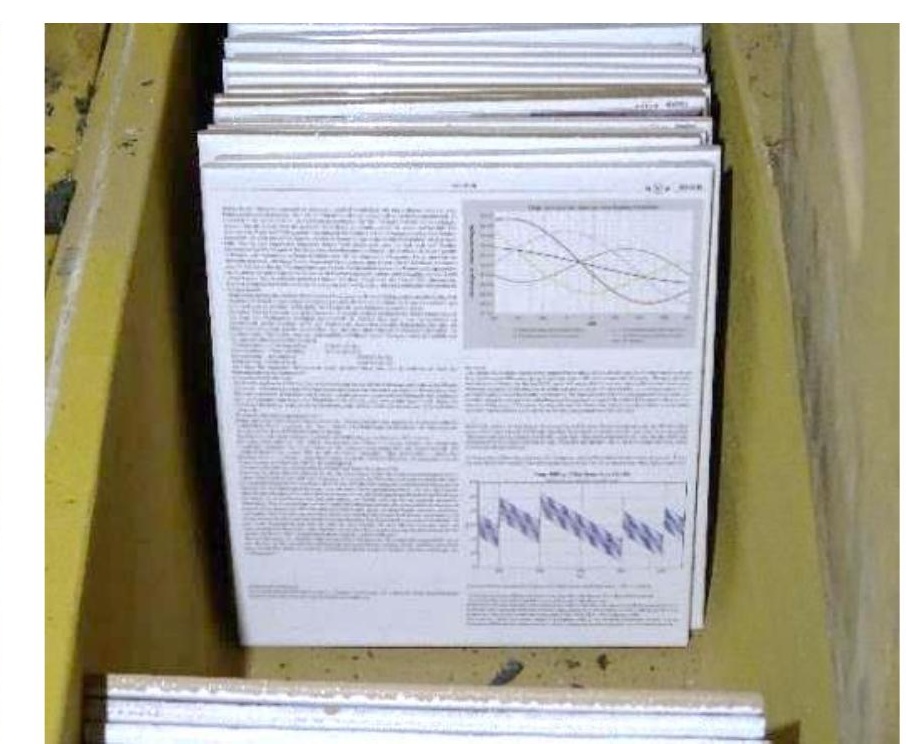




\section{BBC DIE ZEIT}

\section{POPULAR OSCIENCE}

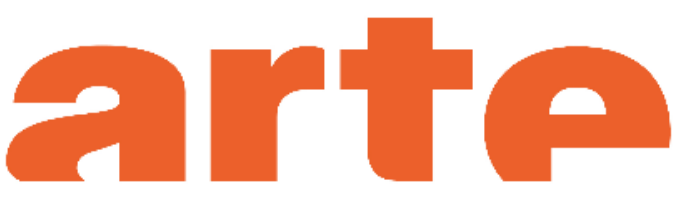

Atetlantic

\section{Ëbe dou Hork Eimes}

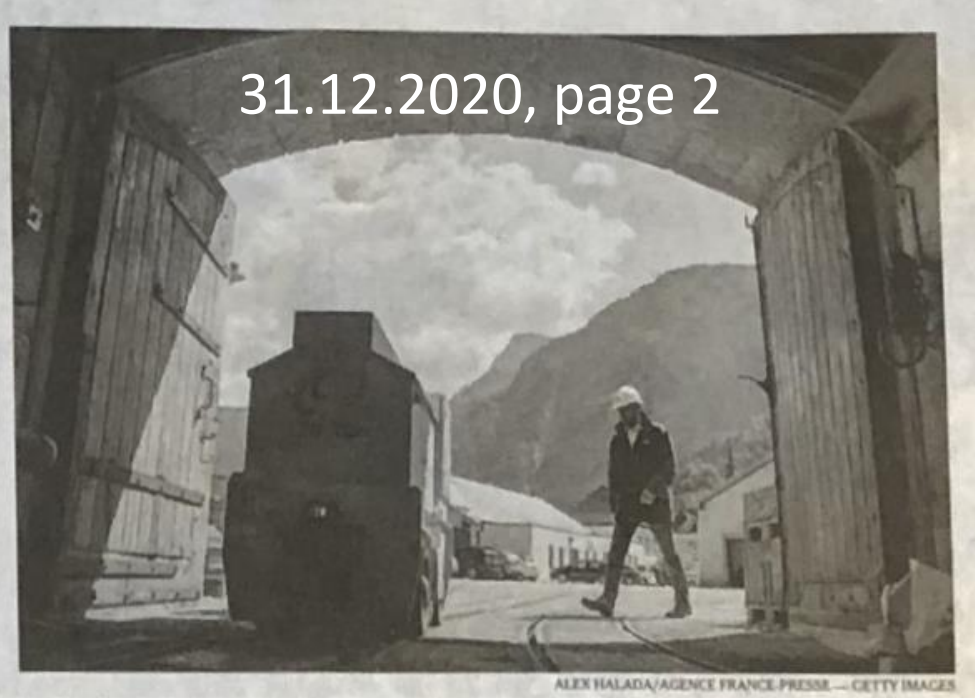

A salt mine in Hallstatt, Austria, that contains a time capsule featuring Times articles.

News That Can Last a Million Years

BY LAUREN JACKSON

In total, Mr. Kunze has added nearly 30 Inside an ancient salt mine, on the edge of Times articles from this year to MOM,
a small Alpine lake in Austria, Martin
archived chronologically. He said he hopes a small Alpine lake in Austria, Martin $\quad$ to add a Times coronavirus retrospective once the pandemic is over. When asked why he has turned to The Times in this process, he saidingemal, Tor the same Times journalists are doing in respect Times jouralsis The Times articles included in the archive go through a specially designed process to be transferred to ceramic tablets. First, a modified color laser printer uses ceramic toner (finely ground ceramic glaze) to print the articles on a paper that will then be coated, glazed, pressed, dried
MOM is covered worldwide in print and TV.

On December 31, on page 2 of The New York Times a retrospect editorial about 2020 and the corona crisis proudly reported, that several NYT articles are part of the MOM archive. 

$M \bigcirc M$
ceramiodotalobutions

Research Programme for Ceramic Data Carriers:

Technical University Vienna,

Material Science and Photonics

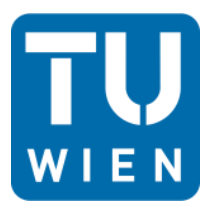

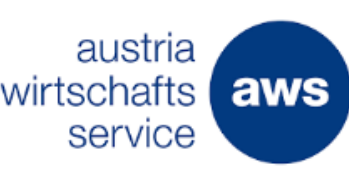

aws

servic tech

\section{9-2021 Grants of 1.000.000+€}




\section{Substrate: High Performance Ceramic and Glass-Ceramic}
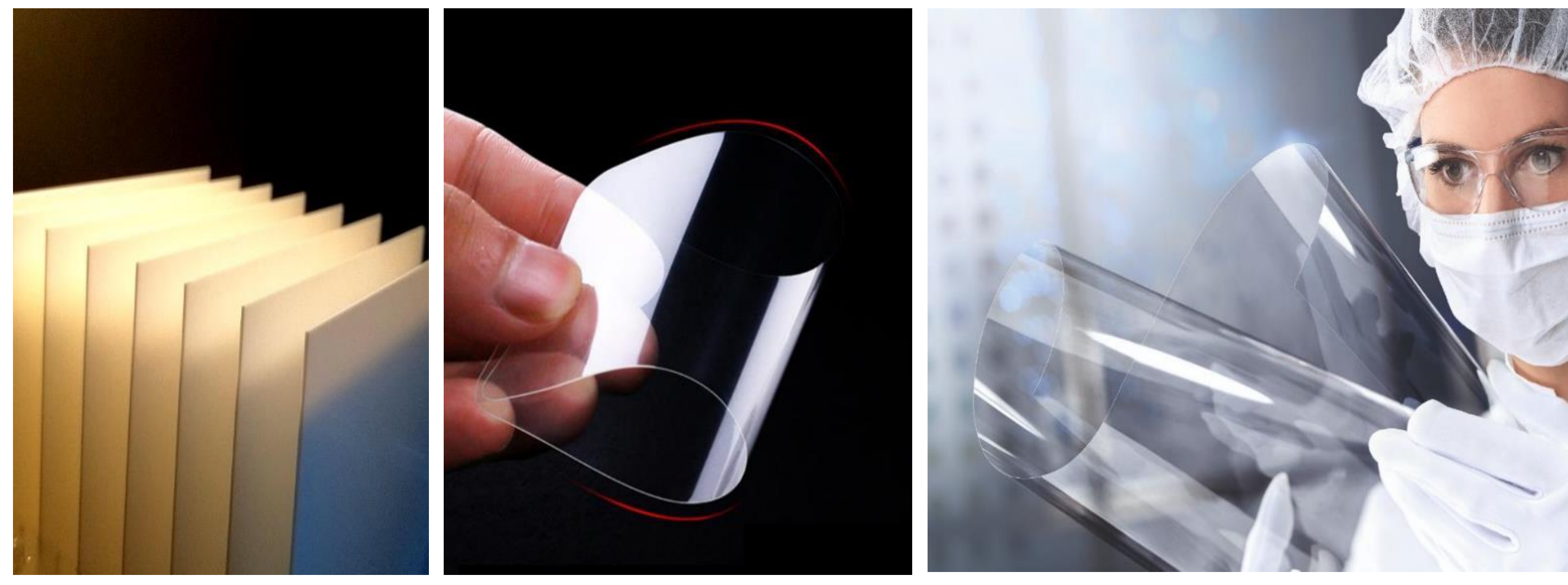

Aluminium Oxide Substrate used in medicine for artificial joints or in the motor- and jetindustry for valves, heat-, corrosionand stress- resistant parts.

We also included the latest developments of advanced glass and glass-ceramic as promising material for long term data carriers into our research program.

Temperature-shock resistant glass-ceramic and thinglass foils are widely used.

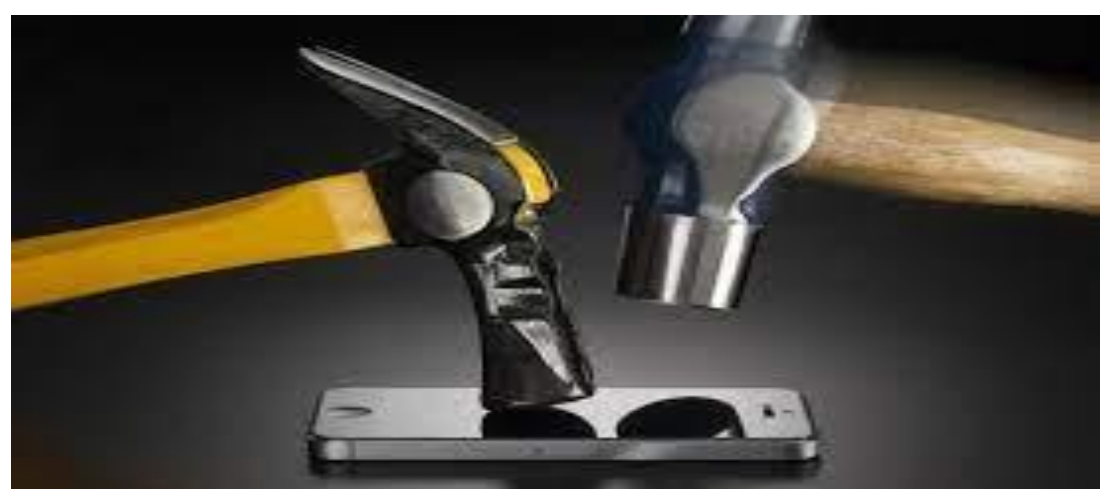




\section{Ceramic Data Layer}

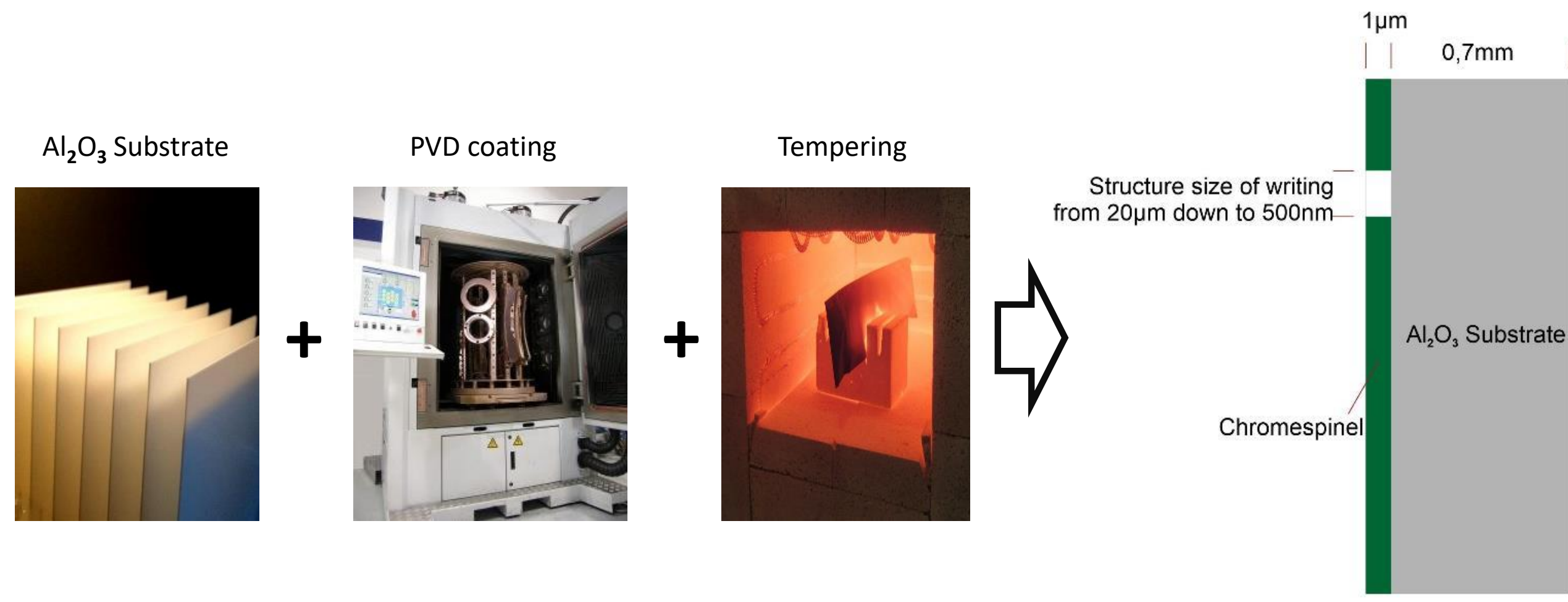

The clue for durable data carriers is a ultra thin and ultra hard coating for the data layer.

The thin data layer is also from ceramic material and even harder (18 Gpa) than the substrate material itself (17 Gpa).

The structural robustness is around $500 \mathrm{Mpa}$.

The European, US and Taiwan patent comprises method and materials. Patent released 4/2021. 


\section{Laser Technology}

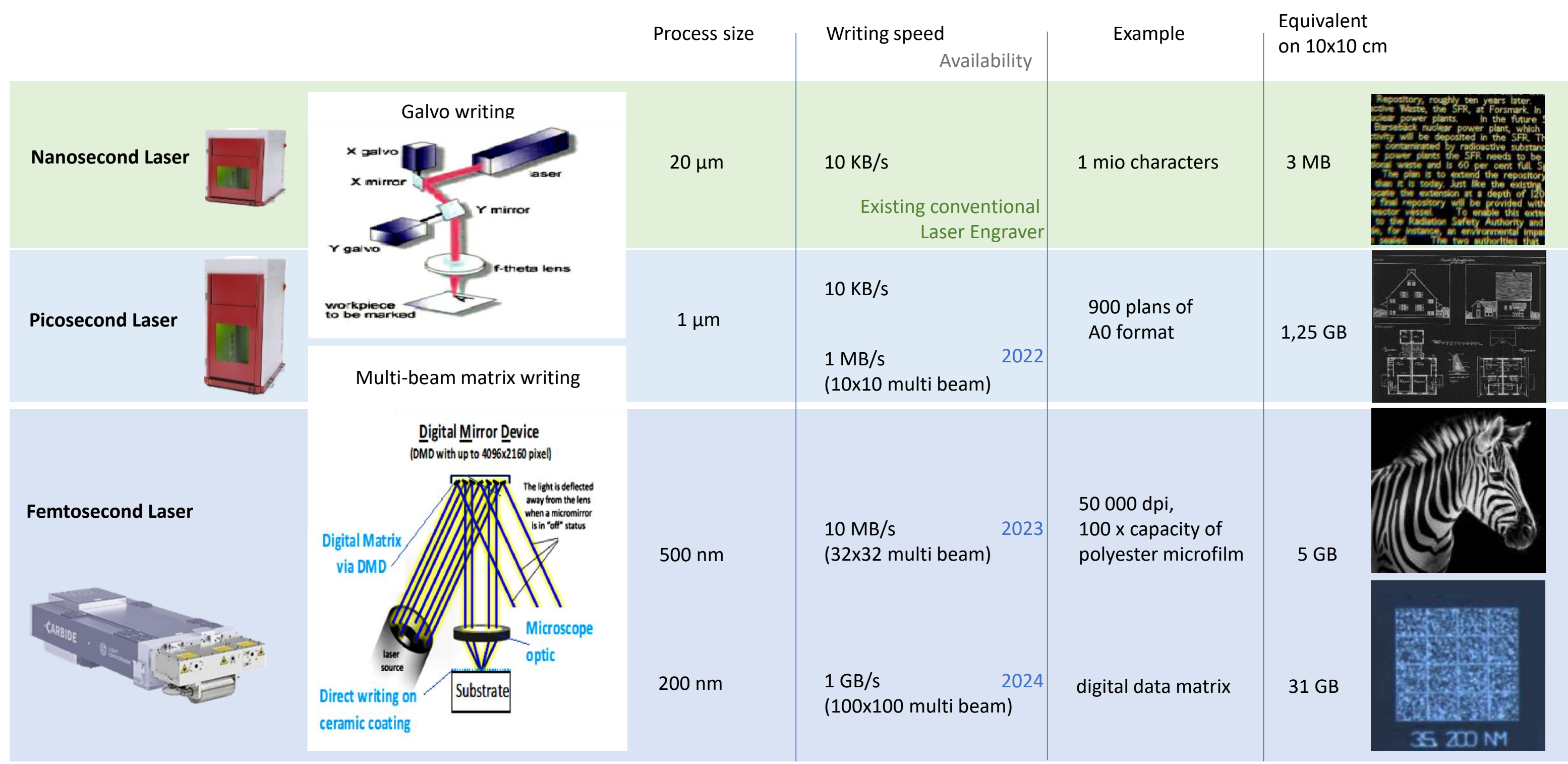


at the Photonics Center at the Technical University in Vienna Sept. 2021

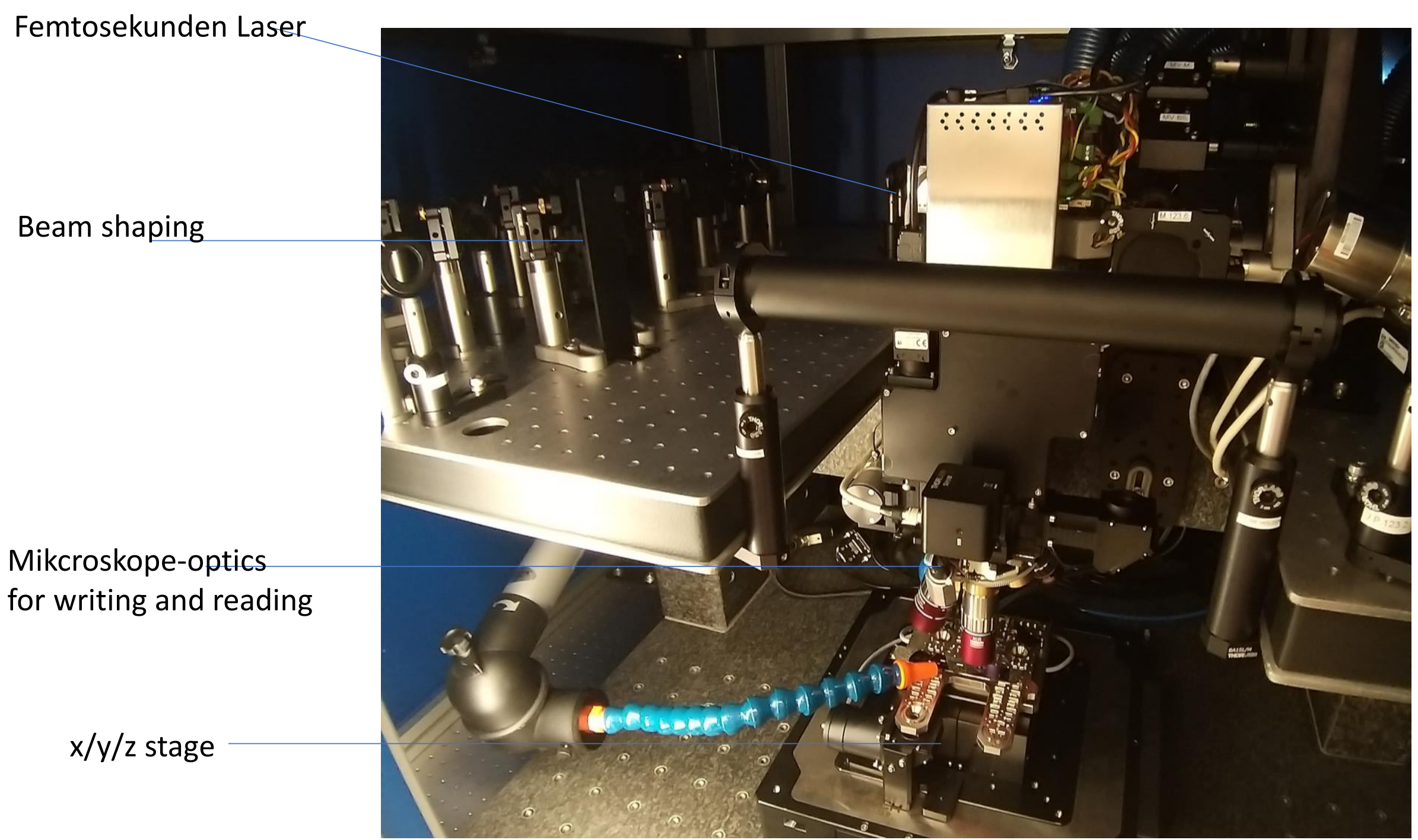



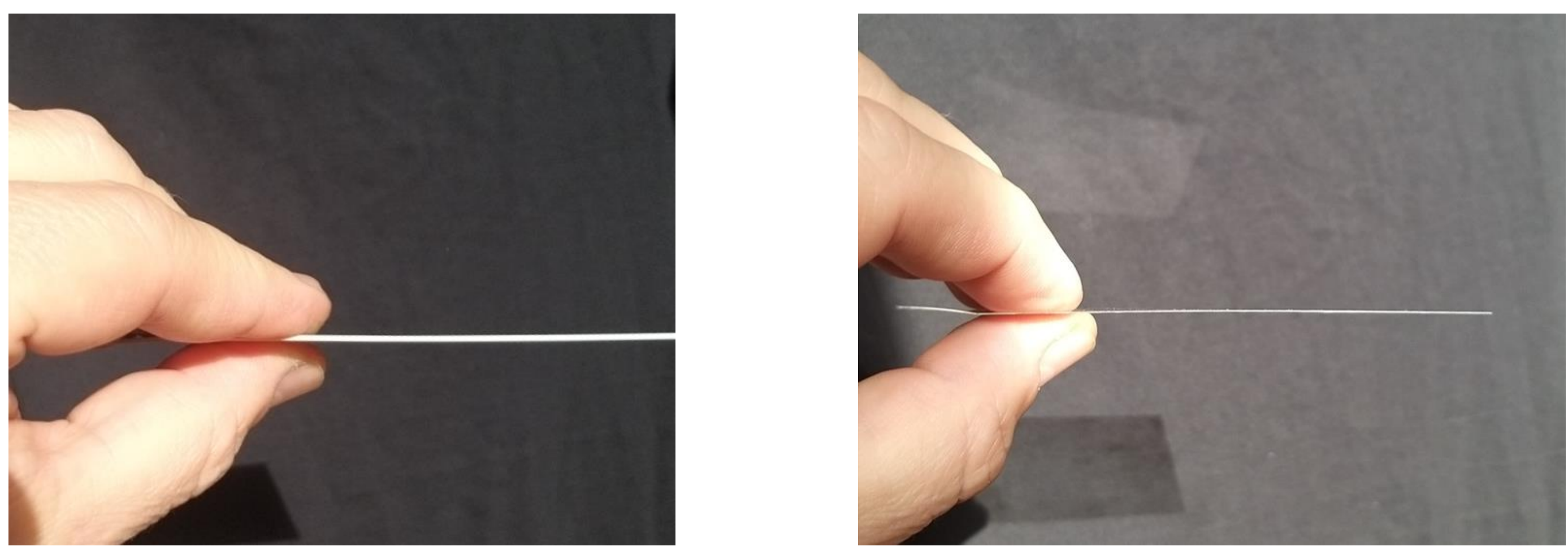

Ceramic Microfilm

Aluminium-Substrate basis

thickness $0,6 \mathrm{~mm}$
Ceramic Microfilm

Glassceramic basis

thickness 0,2 $\mathrm{mm}$ 


\section{0th Anniversary of the Austrian Constitution}

\section{E Bundeskanzleramt}

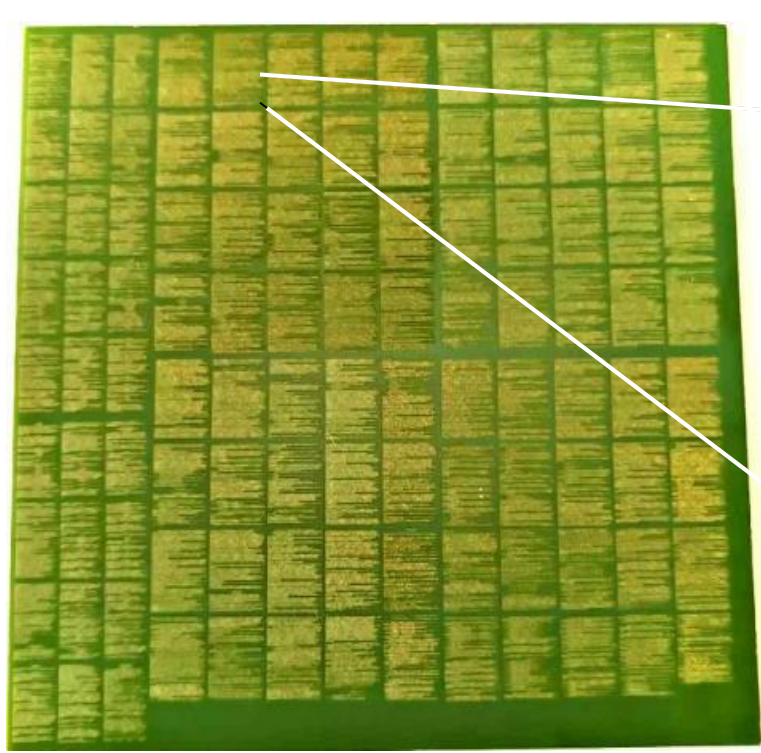

Ceramic Microfilm (10x10cm)

ca. 500000 characters, 200 pages writing time ca. 30 minutes

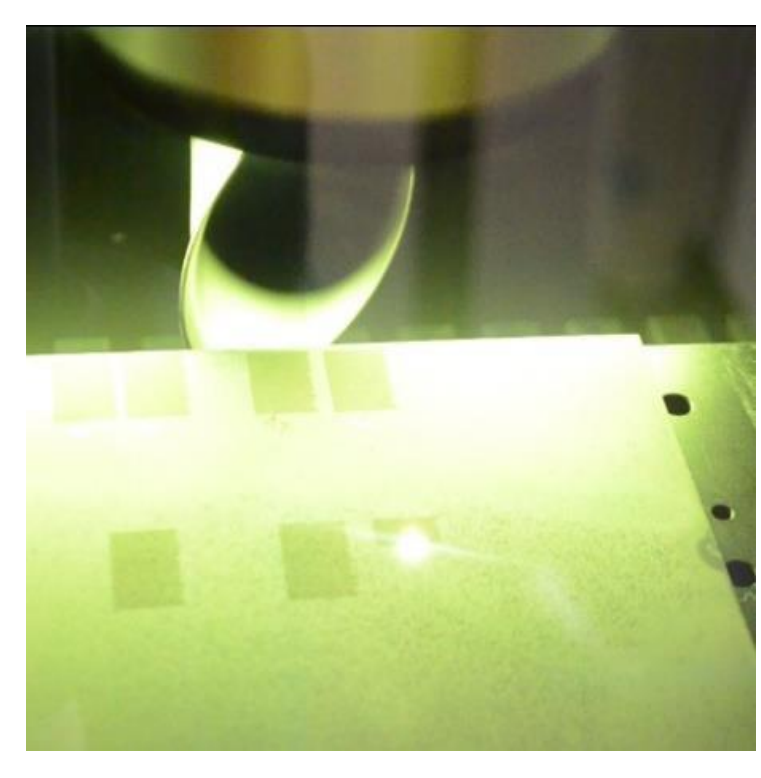

A first pilot project was initiated in cooperation with the Austrian Office of the Federal Chancellor on the occasion of the 100th anniversary of the Austrian Constitution.

The versions from 1920 and 2020 were stored simultaneously in the MOM archive and the Austrian data bunker in the Alps. 


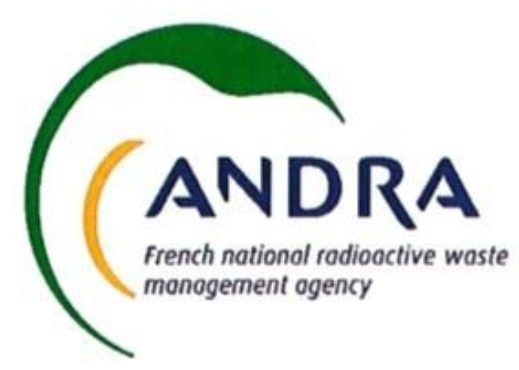

The nuclear industry, especially nuclear waste repositories, require data carriers with extreme longevity to keep the records of the radioactive material for thousands of generations, and also in a way that enables reconstruction of the knowledge in case it gets lost.

The french ANDRA is the first who adopted this technology. 
After writing, before temperature test

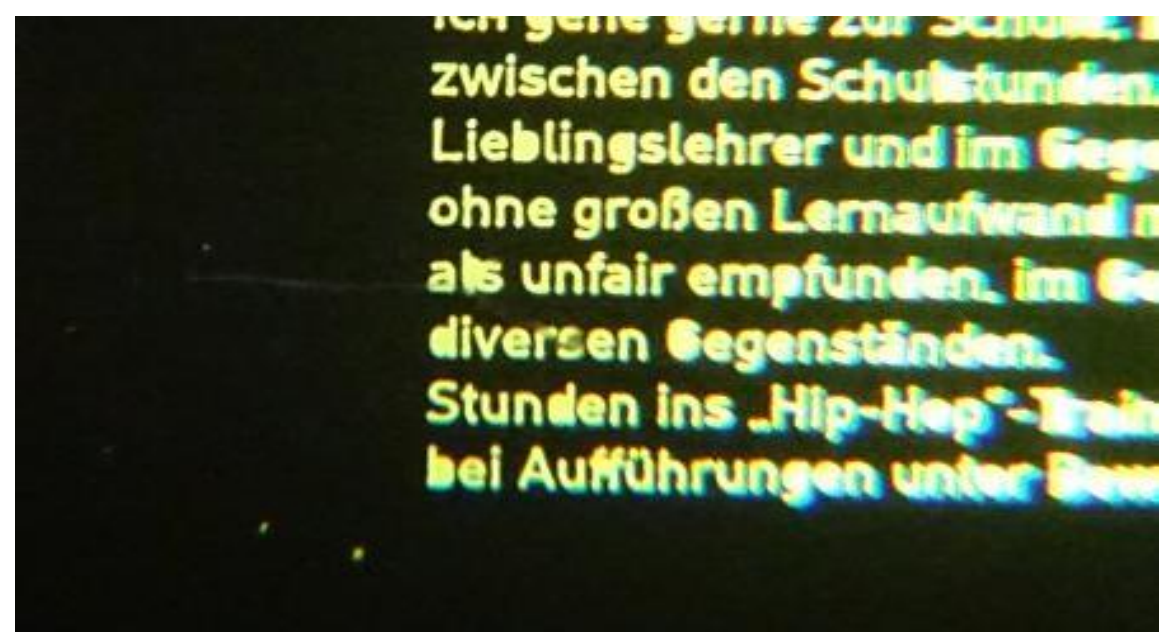

After temperature test $1200^{\circ} \mathrm{C}, 15 \mathrm{~min}$

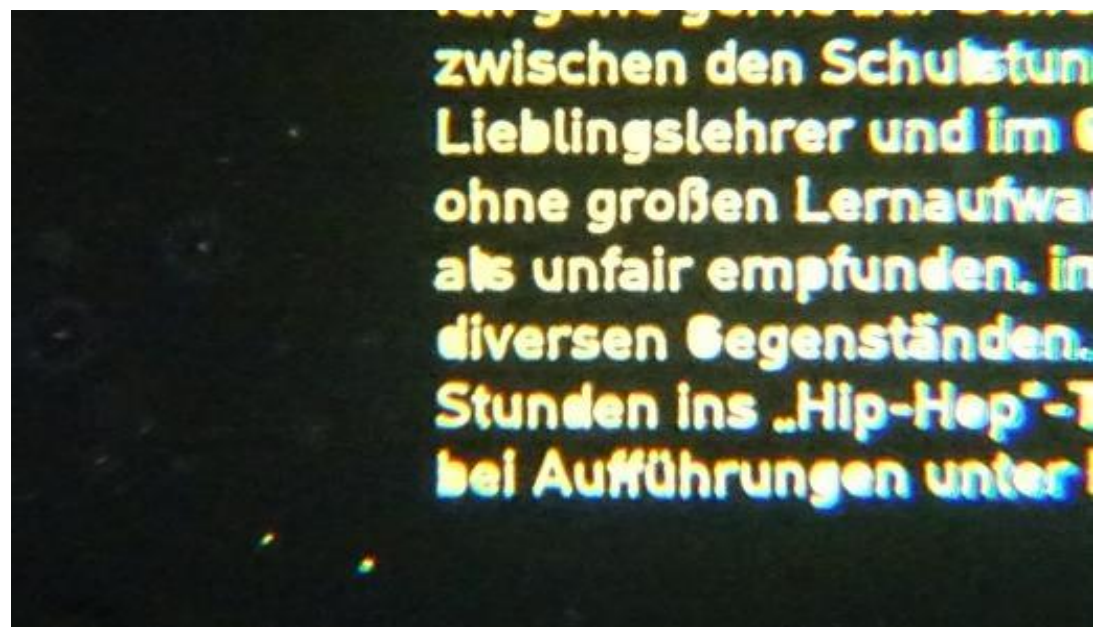

The durability is - in terms of the life circle of a solar system - literally eternal.

$1200^{\circ} \mathrm{C}$ doesn't harm the data carrier at all.

$1200^{\circ} \mathrm{C}$ is the maximum temperature of a major fire.

The actual limit is the substrate with an operating range up to $1500^{\circ} \mathrm{C}$.

Age extrapolation: Durability at room temperature far exceeding $10^{10}$ years 


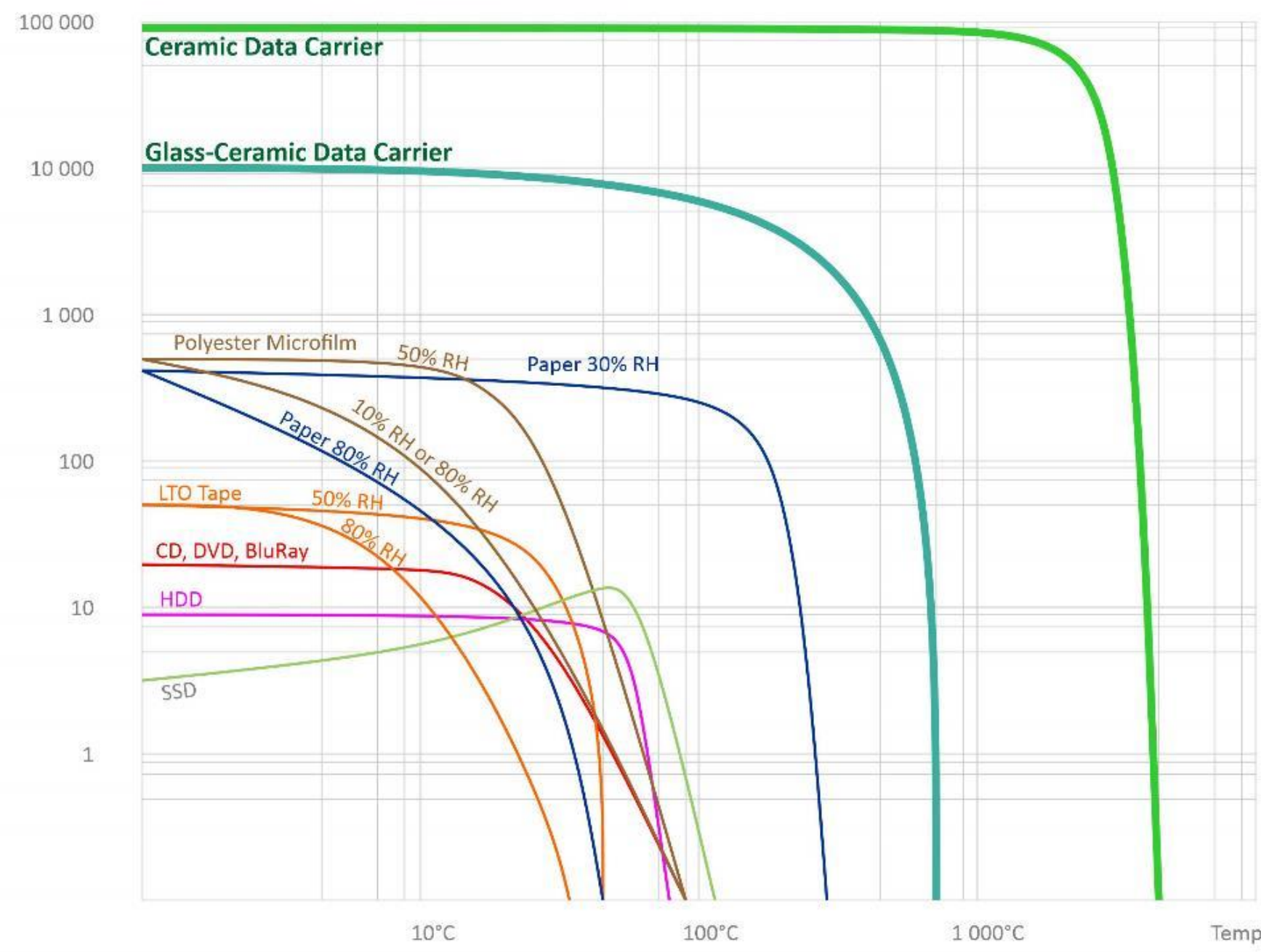

Sources: Heise, IBM, Laboratoire national de métrologie et d'essais, Glasuren und ihre Farben/Wolf Matthes, Council on Library and Information Resources, Library of Congress
Ceramic Data Carriers in comparison to all other types of data carriers have the highest durability and also the highest temperature resistance.

The graph represents the limits from which data becomes illegible, whereas the data carrier itself in some cases may endure higher temperatures. 
This finally lead to data carriers, that withstand all circumstances that conventional data carriers destroy.
- no energy demand

- fire proof

- waterproof

- insensitive to magnetism

- corrosion resistant

- non organic material
- stabile

- worthless material

- audit proof

- basic and intuitively

- non deletable

- selective 


\section{Data $\neq$ Information $\neq$ Knowledge}

- Marker: symbols/icons

- KIF: Key Information : analog text and figures, with decoding- toolbox

- SER, Essential Records/documents: digital with manual

Now, when we can solve the problem of durable data carriers that withstand the ravages of time, the question is: what kind of "data format" is eligible to safekeep information for these projected time horizons in order to create Information from data and to create knowledge from information? Analog?, Digital? Symbols? Icons?

It depends on the complexity of information that needs to be transmitted into a near or remote future.

For the basic information of a marker or the fundamental description of the nature of a repository site, symbols or icons certainly are more efficient than analog text or a binary information format.

And for a greater volume of descriptions, analog text with decoding tools are helpful. An extended dataset that probably also works as basis for machine processing can be kept in a digital form with an introducing manual. 


\section{Marker: symbols/icons}

\section{Nuclear Message}


Stoneage

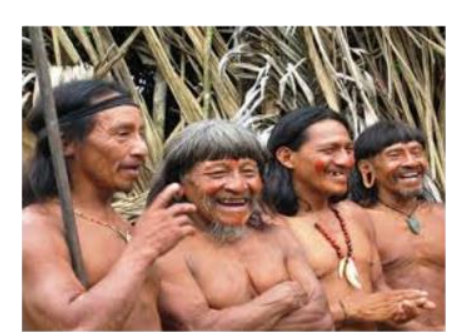

Pre-industrial

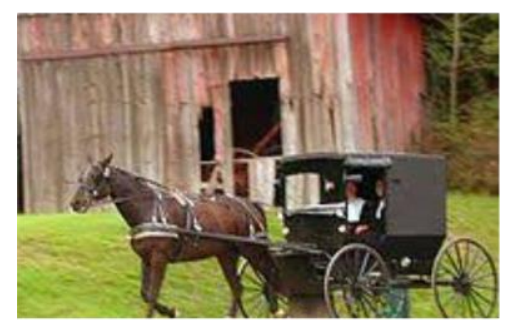

Idiocracy-like

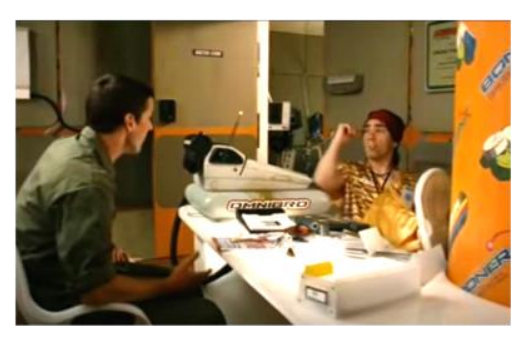

Egyptian

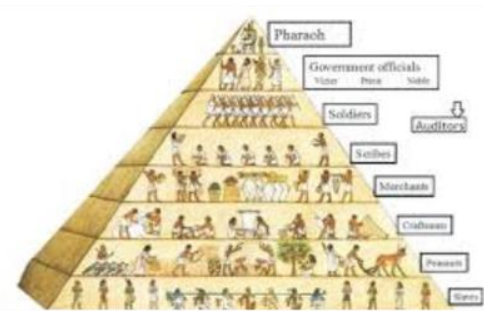

Early-industrial

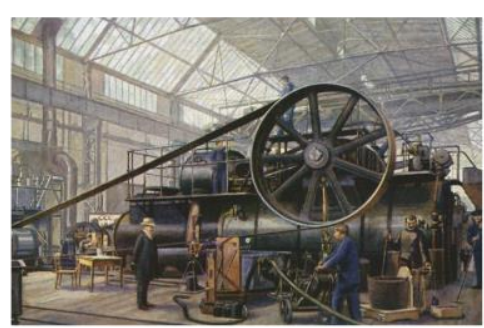

Mad Max -like

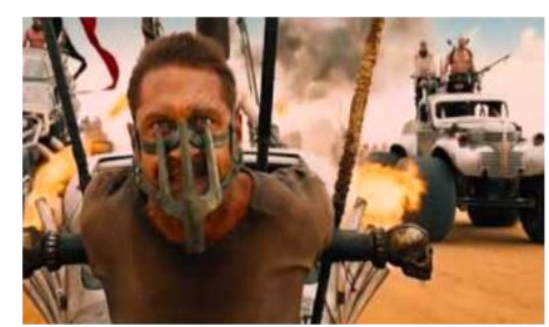

Hellas

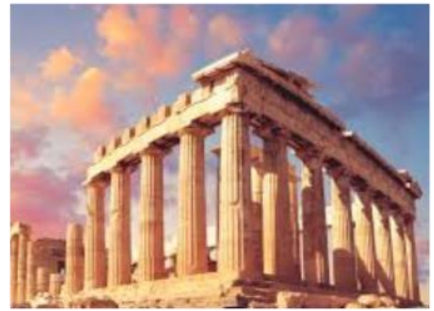

21st-century
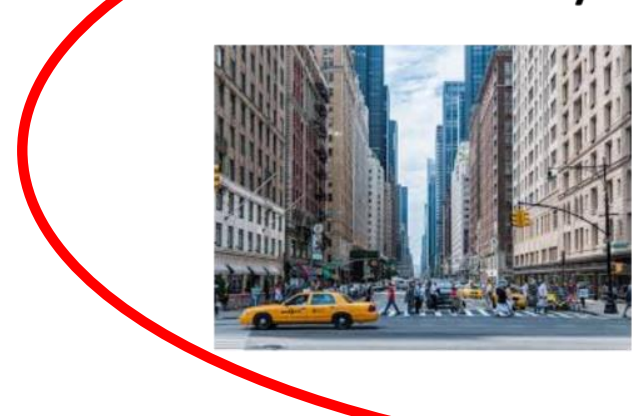

Ant-like-society

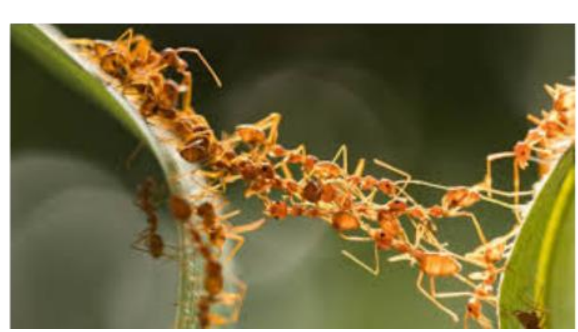

Medieval

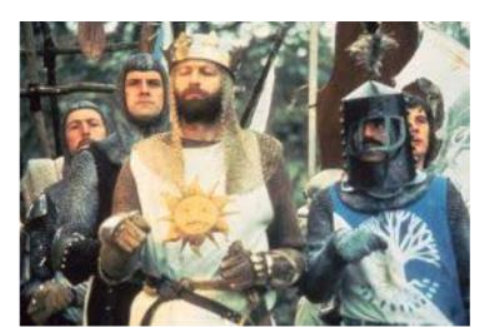

Advanced-technicax

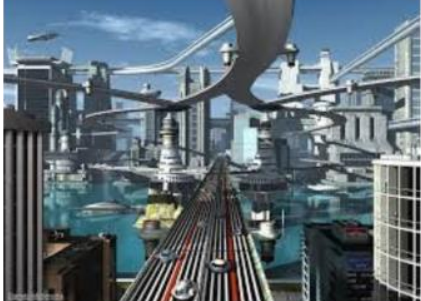

\section{Dolphin-like}

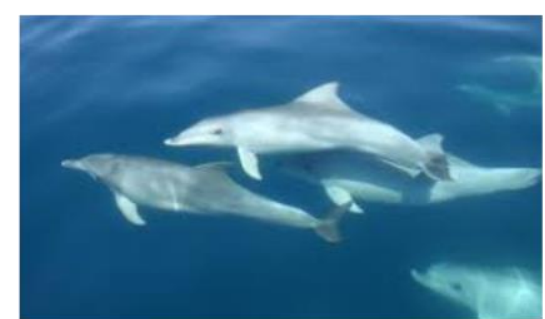

The following is under the assumption that a deep geological repository is designed in a way that it cannot be discovered or let alone opened accidentally only a society of at least a similar technical level comparable to ours from the 1970ies can actually access it: Must haves are: capabilities of deep drilling, ground radar, seismic experience, understanding of geological processes etc 

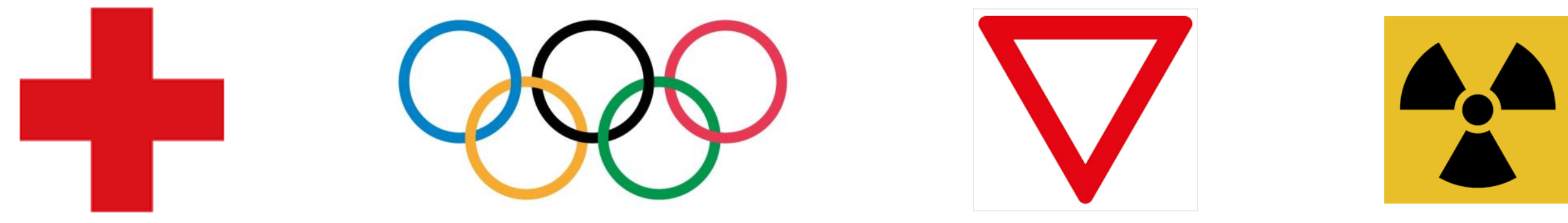

$\delta$

First of all we must acknowledge that most symbols or icons we use have an arbitrary meaning,

In order to understand them a prerequisite knowledge is required.

These symbols barely are useful for a message across thousands of generations. 

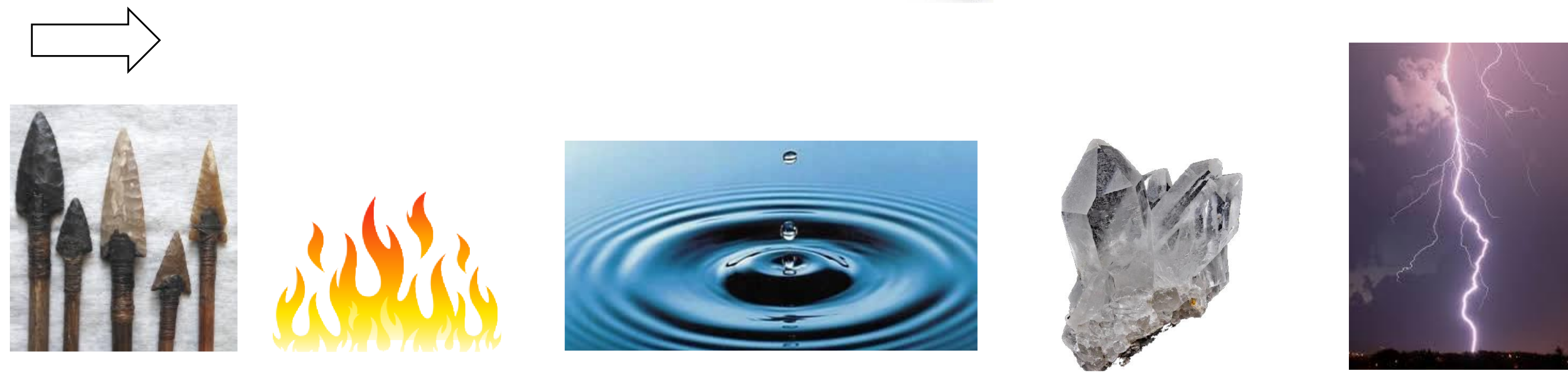

However, there are some symbols which have a literally universal meaning.

A hammer will look the same throughout the universe, it is never a soft ball on a string. 


\section{The Nuclear Message}

A simple but efficient method to describe a nuclear waste repository

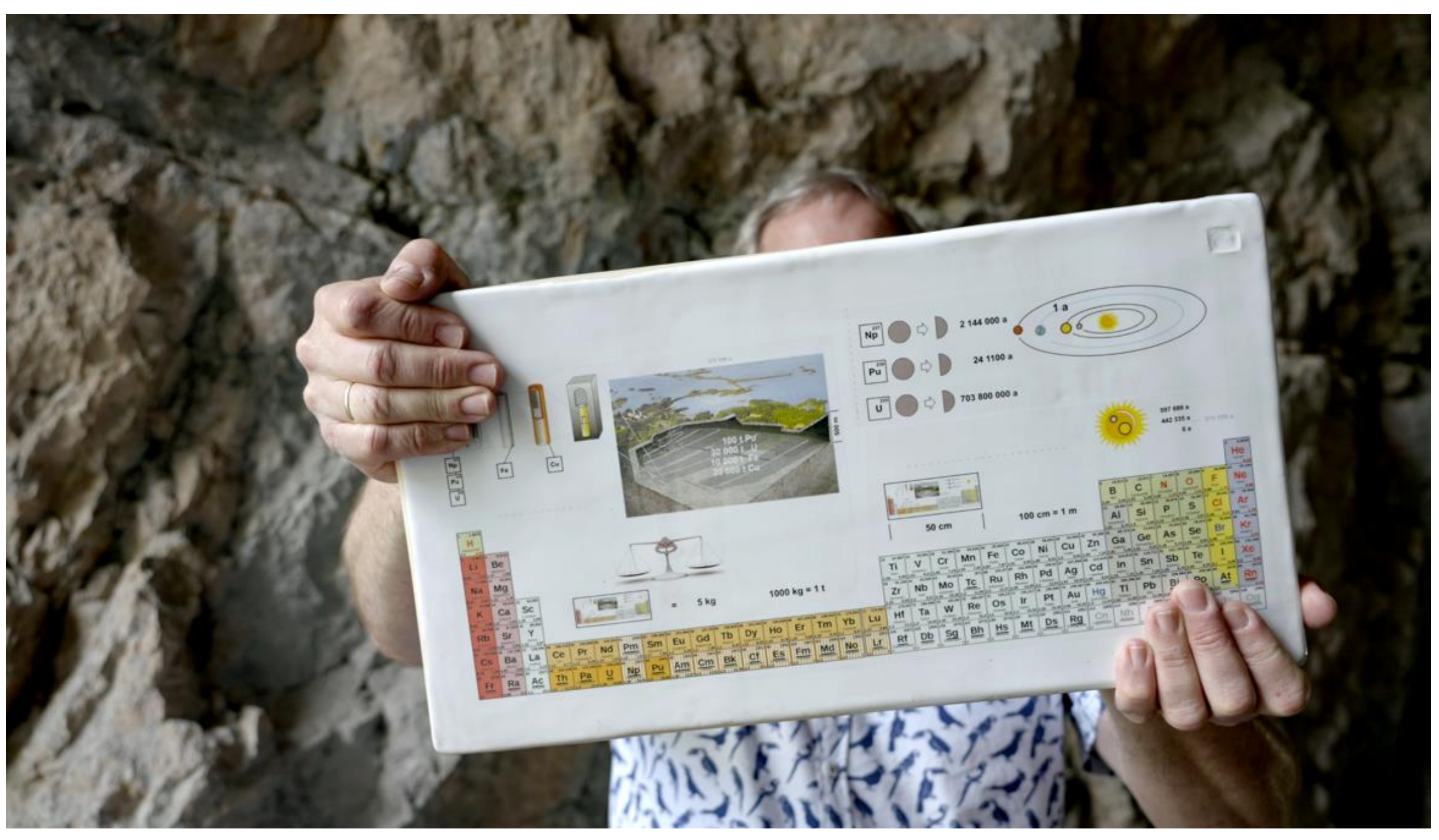

The Nuclear Message, a $3 \mathrm{~cm}$ solid ceramic plate with a ceramic color print below a hard glazed surface. 


\section{The Order of Matter is Universal}

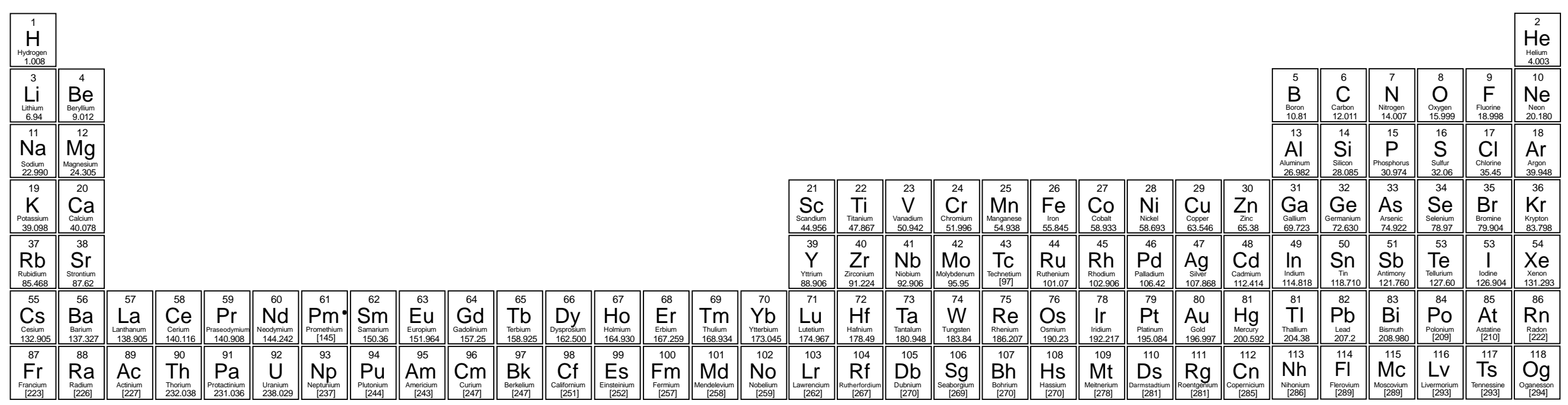

The principle which is behind the periodic table of elements was detected concurrently twice on earth. This is not a coincident - it is a natural, universumwide order of the elements.

As soon as a civilisation recognises this order, the configuration as table is only a consequence.

The Periodic Table simultaneously explains our numeral system which in consequence allows to describe isotopes.

No matter how a future writing system looks like, the mere position in the table defines the respective element. 


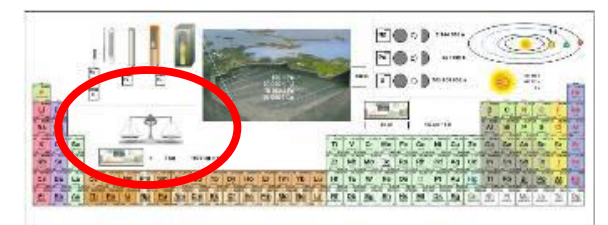

$\frac{\mathrm{Pu}}{\mathrm{U}^{\mathrm{m}}}$

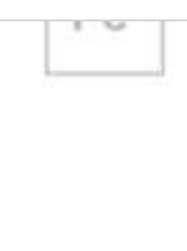

\section{definition of weight}
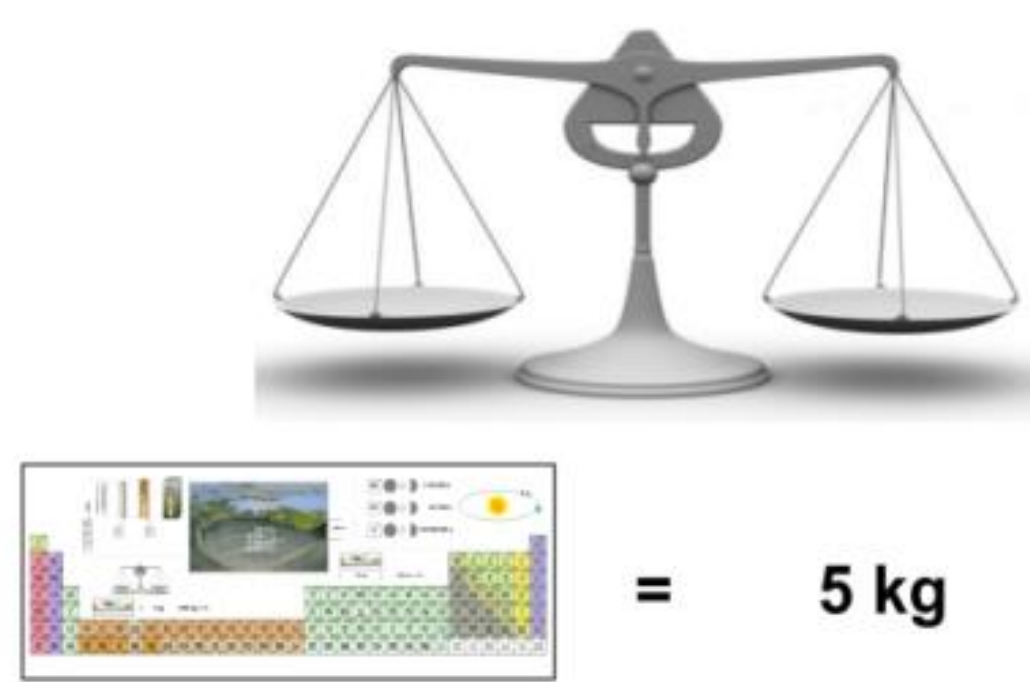

\section{$=\quad 5 \mathrm{~kg}$}

$1000 \mathrm{~kg}=1 \mathrm{t}$

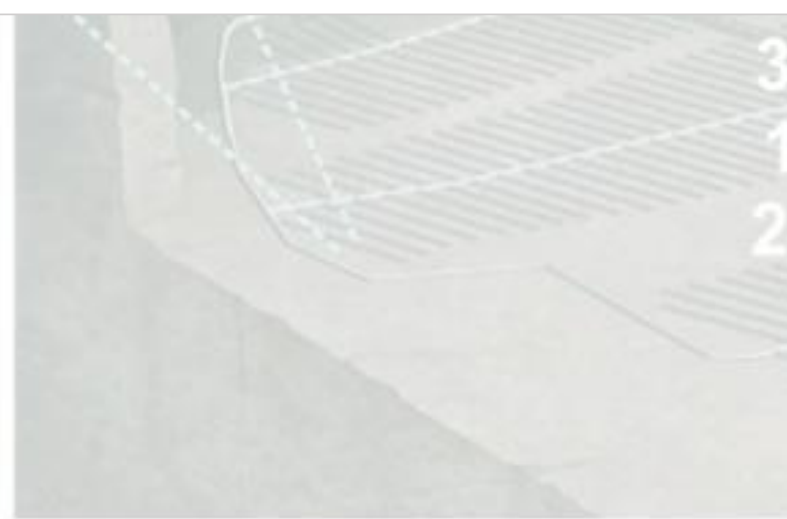

The plate itself works as a rough "unit" for weight.

From early human civilization, a balance looks identic. Everywhere, where gravity exists, a balance has a similar design.

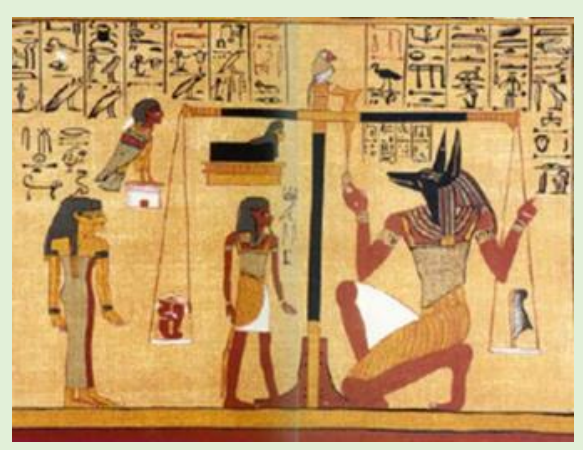



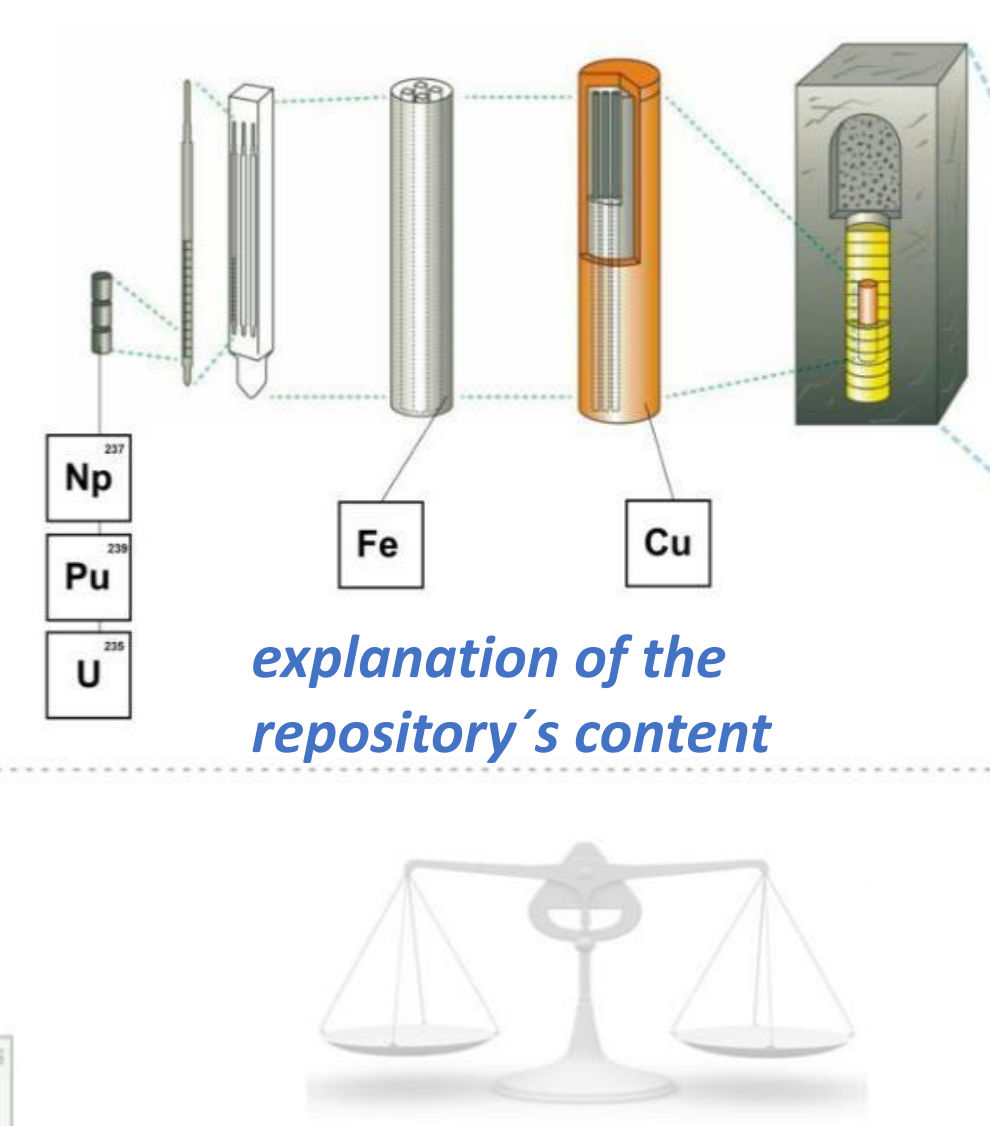

\section{illustration of the deposit}

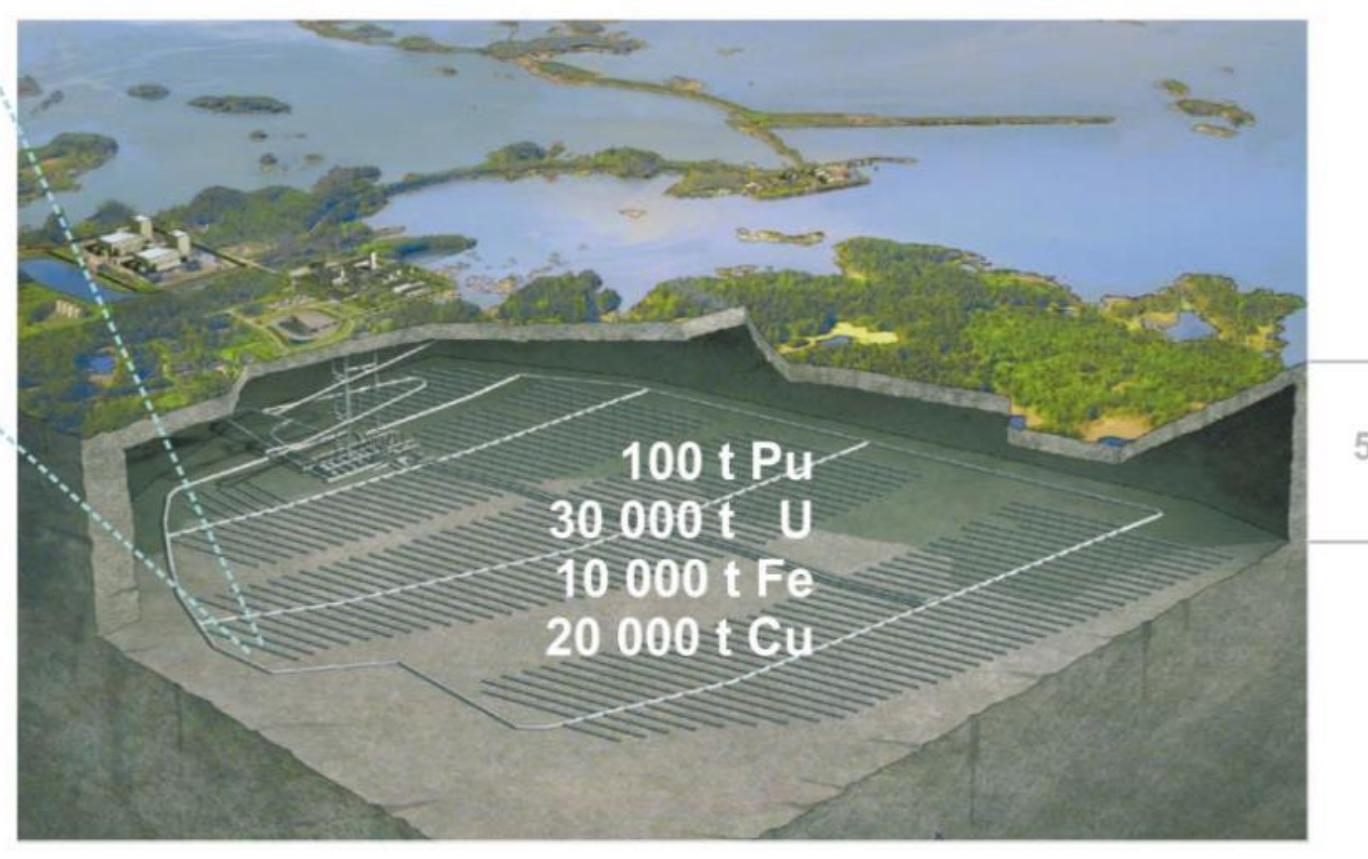

amount of the content
The containers and the material from which they are made, and the respective isotopes are indicated.

As well as a depiction of the repository itself and the amount of material stored there. 

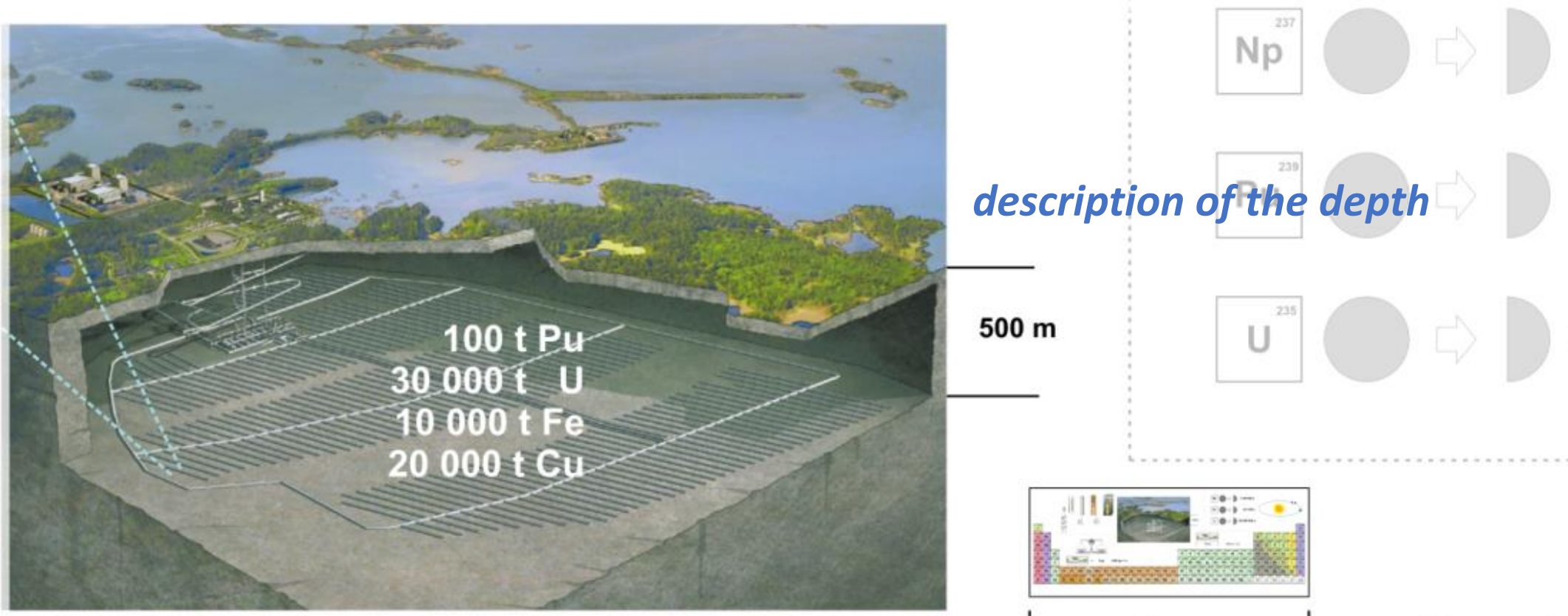

The size of the plate serves as a rough unit for length.

$500 \mathrm{~m}$

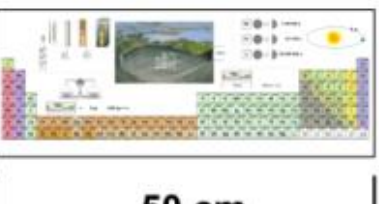

$50 \mathrm{~cm}$

$100 \mathrm{~cm}=1 \mathrm{~m}$

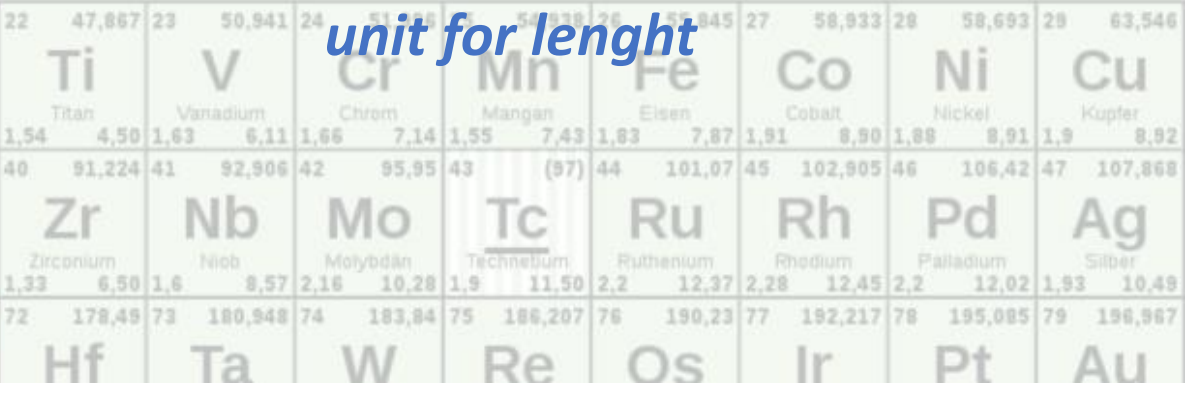


Definition of one year and double-check via half-life periods. Explaining our present era by rare astronomical events.
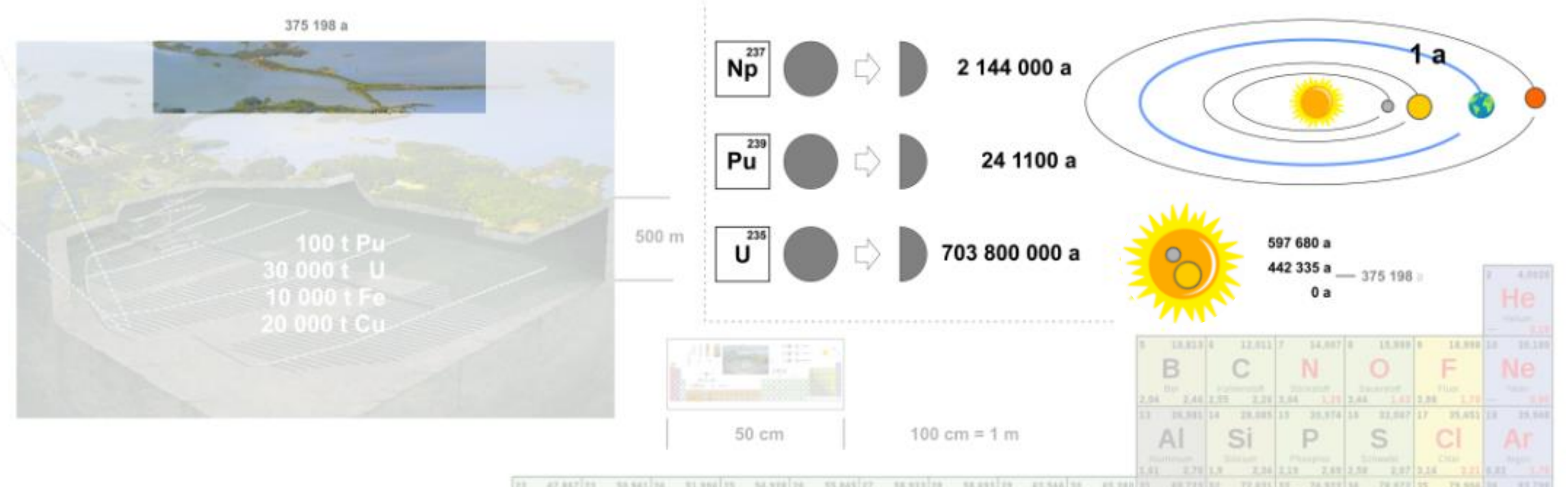

$100 \mathrm{~cm}=1 \mathrm{~m}$

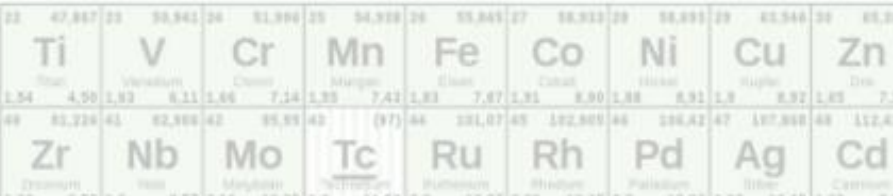

Gd Tb Dy Ho Er Tm $\mathrm{Yb}$ Lu Hf Ta W Re Os Ir Pt Au

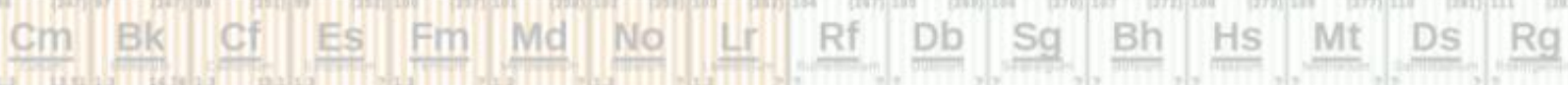

One year as unit for time is defined by the depiction of the earth's orbit around the sun. This can be doublechecked by the half-life period of some radioactive elements.

To explain, when our current presence is, a very rarely occurring constellation is chosen to assist:

Simultaneous transits of Mercury and Venus (the event when both planets are exactly between the sun and the earth and appear as dark spots in front of the solar disc).

The last one occurred in $373173 \mathrm{BC}$ and the next will be in the year 69163 and the next but one in 224508 .

Hence the last one is 375198 years ago. This number is also positioned on top of the illustration of the repository site. 


\section{Nuclear Message with built-in chronometer}

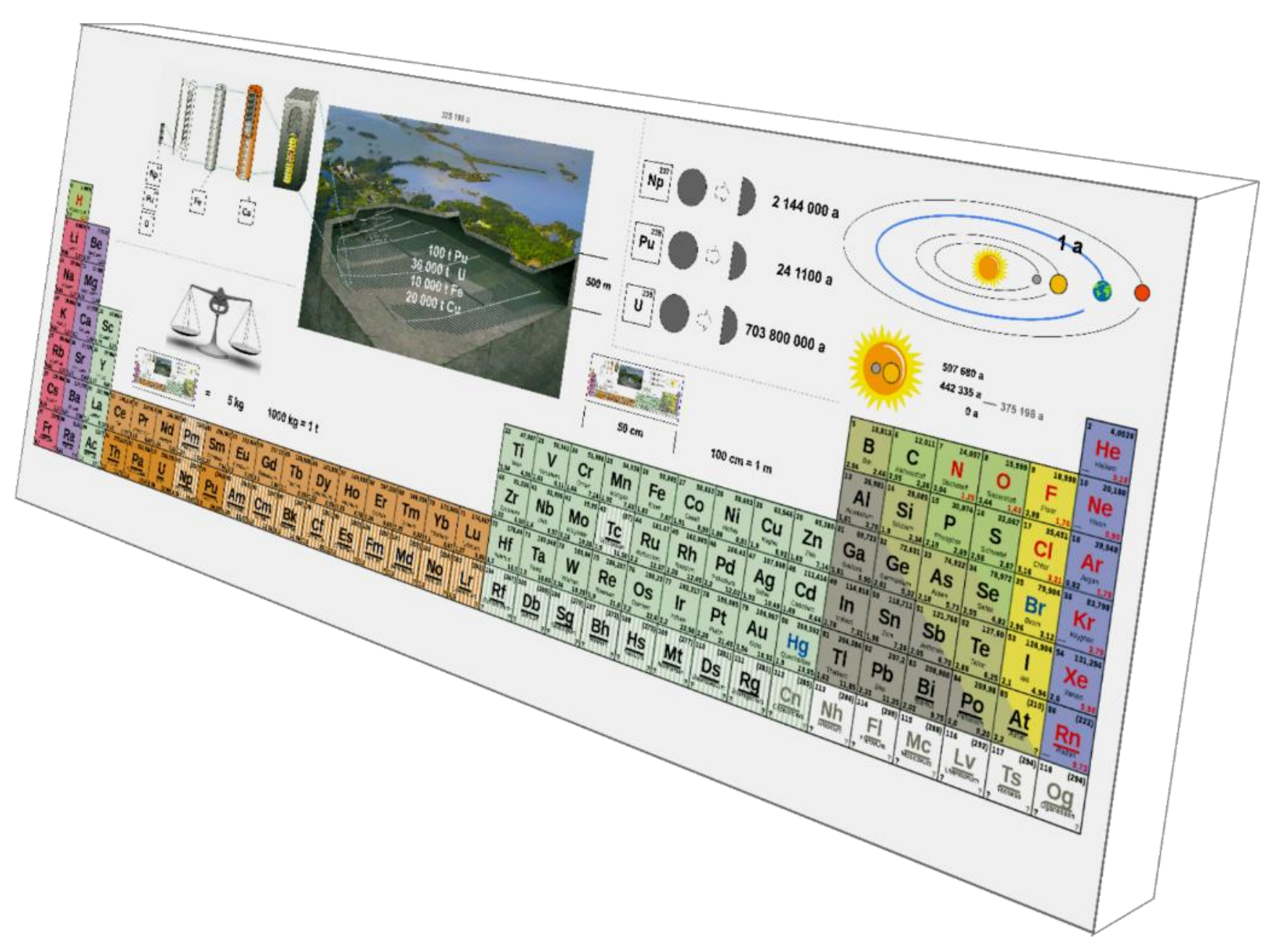

Ceramic material is a "clock“:

Silicate containing material indicates its "age" by thermoluminescence.

Thermoluminescence dating shows how much time have passed by, since the material was last heated over $600^{\circ} \mathrm{C}$. We know the effect of thermo-luminescence since 1950 and it is used to determine the age of rock or ceramics.

Because the plate is produced at $1200^{\circ} \mathrm{C}$, the clock is now "set to zero".

The calculated age of the plate can be doublechecked with the astronomical events of the simultaneous transits.

In 50000 years in the future, scientists can figure out the age of this ceramic object (namely 50000 years).

They can then estimate the rate of decrease of radioactivity and the nature of the content at that point in time. 


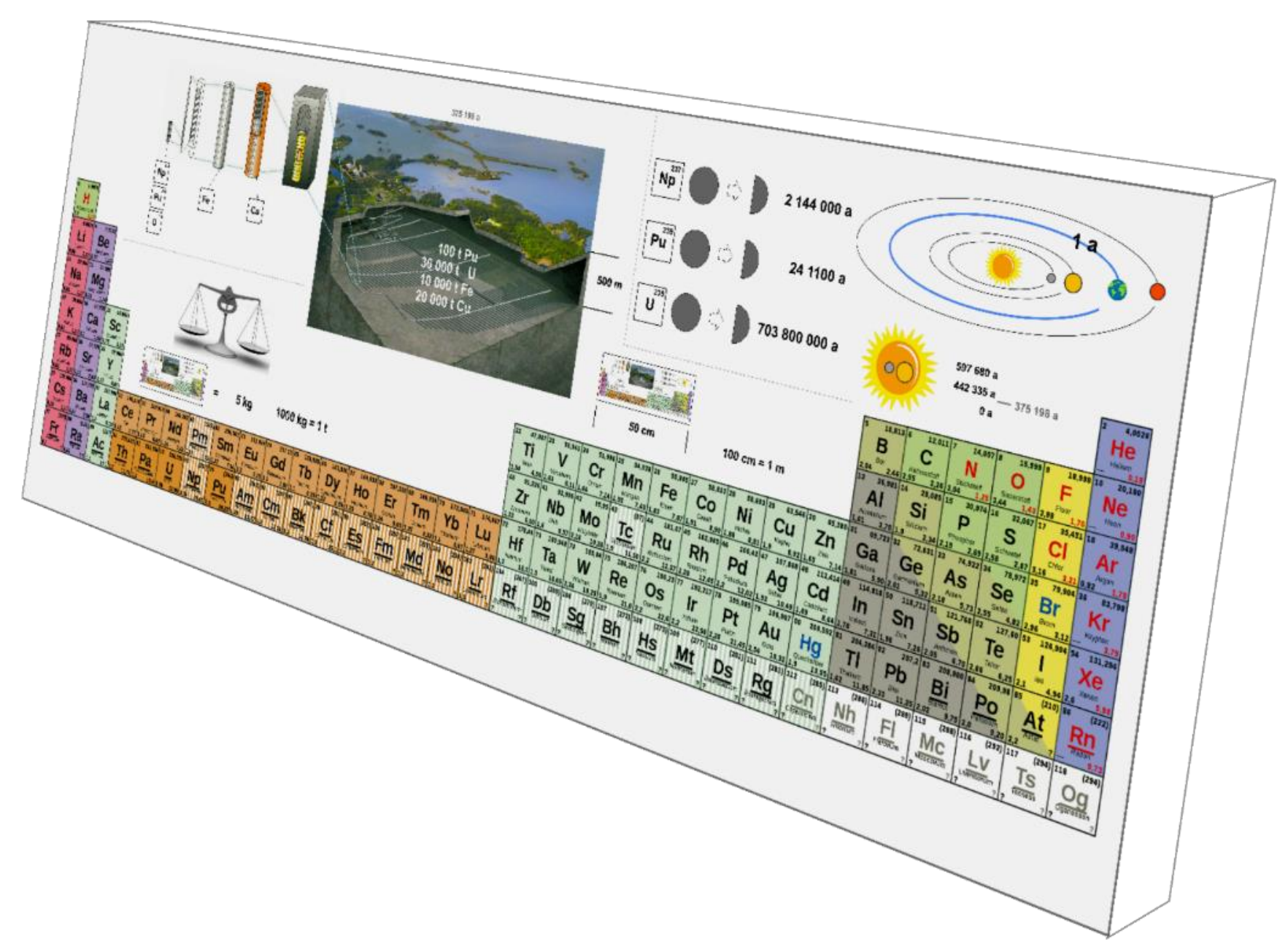

The Nuclear Message is a $3 \mathrm{~cm}$ solid ceramic plate with ceramic color print below a hard glazed surface

Even if the surface got opaque (by windsand erosion) - once fired at $1200^{\circ} \mathrm{C}$ the glaze becomes transparent again and reveals the images. 


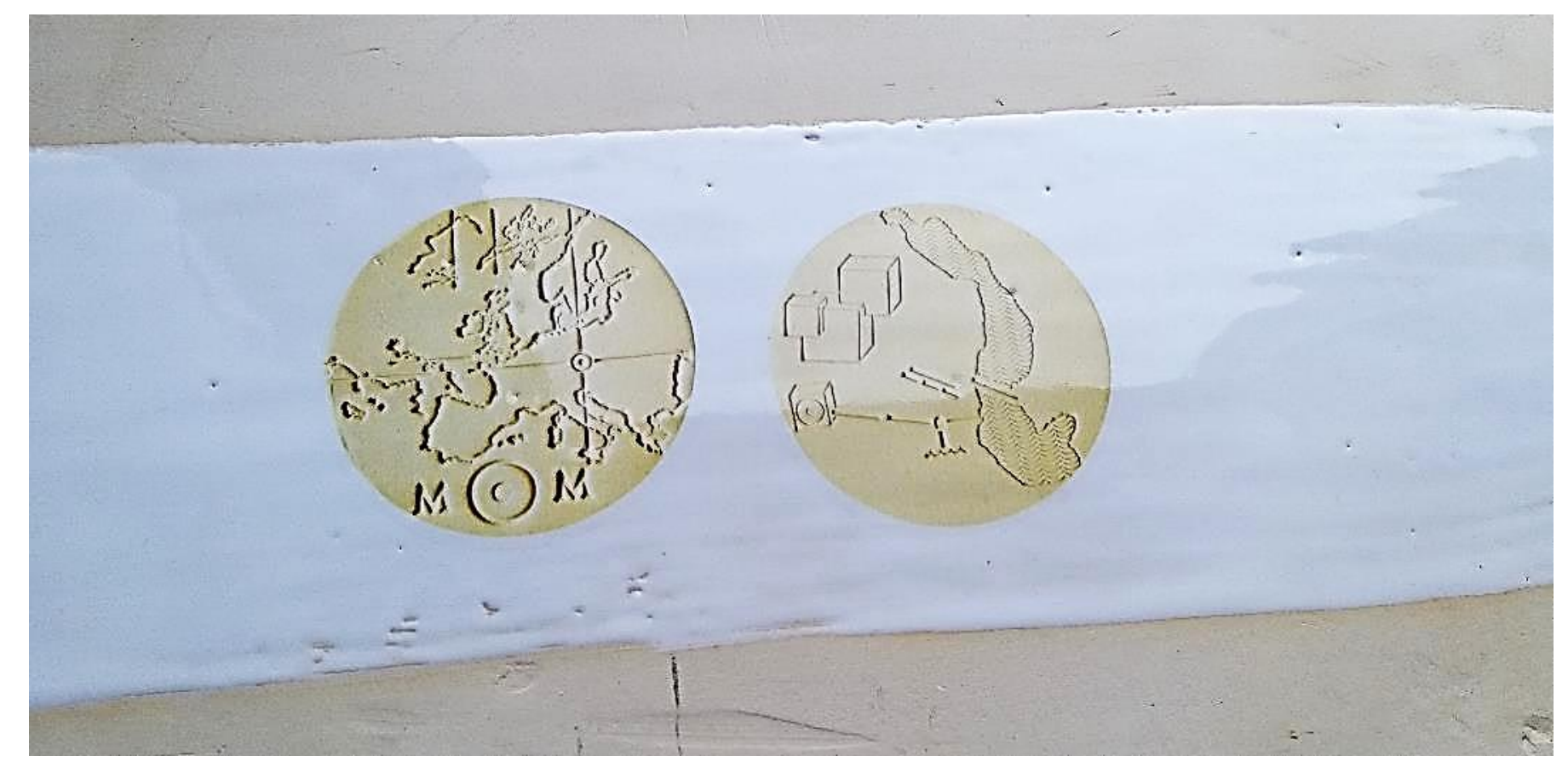

Similar to the method which the MOMToken uses, the backside has information about the exact position by using landmarks such as coastlines, peaks or lakes. Those landmarks will change significantly, e.g. by rising sea level. But future finders, who can decode the front side will have the insight about geological processes and can therefore reconstruct a former coastline at a particular point in time.

The continental drift is about $1 \mathrm{~cm} /$ year. This sums up to $1 \mathrm{~km}$ per 100.000 years and has no sigificant impact on the continent's shape within 1 Mio years. 


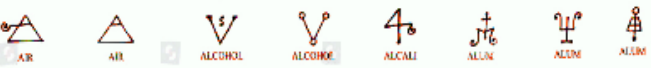

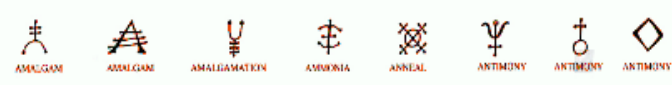

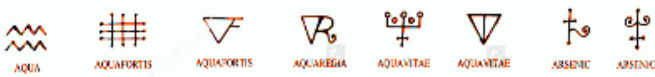

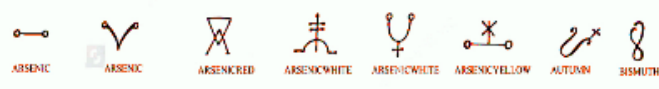

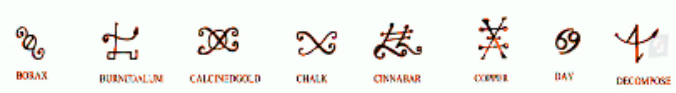

We know that we don't comprehend $95 \%$ of the universe's matter and energy.

It's very likely that new insights lead to a substantially different understanding matter, energy and time, or the fundamental forces.

However, even if a highly advanced society finds the Nuclear Message, the knowledge which is behind the Nuclear Message must have been part of their epistemological path.

Because it is very unlikely that quantum physics is invented before the steam machine... 


\section{Conclusion:}

- The position can be described by landmarks

- The content is explained by the Periodical System of the Elements

- Our decimal system is shown by the numbering of the elements

- The amount of the respective materials can be derived from the Nuclear Message's weight serving as unit

- The depth is defined by the Nuclear Message's size

- A year is defined by

- half-life periods of selected nuclides

- depiction of the inner solar system and the earth's orbit

- The age of the repository is shown by

- thermoluminescence of the Nuclear Message`s material

- astronomical constellations which happen only three times within 500.000 years

- The respective current content at any point in time can be calculated by the time passed by since construction

- The Nuclear Message is inexpensive and can be distributed in large amounts in the region of the repository 